\title{
Vertical profile of tropospheric ozone derived from synergetic retrieval using three different wavelength ranges, UV, IR, and microwave: sensitivity study for satellite observation
}

\author{
Tomohiro O. Sato ${ }^{1}$, Takao M. Sato ${ }^{2,1}$, Hideo Sagawa ${ }^{3}$, Katsuyuki Noguchi ${ }^{4}$, Naoko Saitoh ${ }^{5}$, Hitoshi Irie $^{5}$, \\ Kazuyuki Kita $^{6}$, Mona E. Mahani ${ }^{1,7}$, Koji Zettsu ${ }^{1}$, Ryoichi Imasu ${ }^{8}$, Sachiko Hayashida ${ }^{4}$, and Yasuko Kasai ${ }^{1,9,10,11}$ \\ ${ }^{1}$ Big Data Analytics Laboratory, National Institute of Information and Communications Technology, Tokyo, Japan \\ ${ }^{2}$ Institute of Space and Astronautical Science, Japan Aerospace Exploration Agency, Kanagawa, Japan \\ ${ }^{3}$ Department of Astrophysics and Atmospheric Sciences, Kyoto Sangyo University, Kyoto, Japan \\ ${ }^{4}$ Faculty of Science, Nara Women's University, Nara, Japan \\ ${ }^{5}$ Center for Environmental Remote Sensing, Chiba University, Chiba, Japan \\ ${ }^{6}$ College of Science, Ibaraki University, Ibaraki, Japan \\ ${ }^{7}$ Department of Geophysics, Tohoku University, Miyagi, Japan \\ ${ }^{8}$ Atmosphere and Ocean Research Institute, The University of Tokyo, Chiba, Japan \\ ${ }^{9}$ Terahertz Technology Research Center, National Institute of Information and Communications \\ Technology, Tokyo, Japan \\ ${ }^{10}$ Department of Chemical Science and Engineering, Tokyo Institute of Technology, Tokyo, Japan \\ ${ }^{11}$ Graduate School of Pure and Applied Sciences, Tsukuba University, Ibaraki, Japan \\ Correspondence: Yasuko Kasai (ykasai@nict.go.jp)
}

Received: 5 April 2017 - Discussion started: 29 May 2017

Revised: 26 January 2018 - Accepted: 29 January 2018 - Published: 26 March 2018

\begin{abstract}
We performed a feasibility study of constraining the vertical profile of the tropospheric ozone by using a synergetic retrieval method on multiple spectra, i.e., ultraviolet (UV), thermal infrared (TIR), and microwave (MW) ranges, measured from space. This work provides, for the first time, a quantitative evaluation of the retrieval sensitivity of the tropospheric ozone by adding the MW measurement to the UV and TIR measurements. Two observation points in East Asia (one in an urban area and one in an ocean area) and two observation times (one during summer and one during winter) were assumed. Geometry of line of sight was nadir downlooking for the UV and TIR measurements, and limb sounding for the MW measurement. The retrieval sensitivities of the ozone profiles in the upper troposphere (UT), middle troposphere (MT), and lowermost troposphere (LMT) were estimated using the degree of freedom for signal (DFS), the pressure of maximum sensitivity, reduction rate of error from the a priori error, and the averaging kernel matrix, derived based on the optimal estimation method. The measurement noise levels were assumed to be the same as those for currently
\end{abstract}

available instruments. The weighting functions for the UV, TIR, and MW ranges were calculated using the SCIATRAN radiative transfer model, the Line-By-Line Radiative Transfer Model (LBLRTM), and the Advanced Model for Atmospheric Terahertz Radiation Analysis and Simulation (AMATERASU), respectively. The DFS value was increased by approximately 96,23 , and $30 \%$ by adding the MW measurements to the combination of UV and TIR measurements in the UT, MT, and LMT regions, respectively. The MW measurement increased the DFS value of the LMT ozone; nevertheless, the MW measurement alone has no sensitivity to the LMT ozone. The pressure of maximum sensitivity value for the LMT ozone was also increased by adding the MW measurement. These findings indicate that better information on LMT ozone can be obtained by adding constraints on the UT and MT ozone from the MW measurement. The results of this study are applicable to the upcoming air-quality monitoring missions, APOLLO, GMAP-Asia, and uvSCOPE. 


\section{Introduction}

The World Health Organization (WHO) estimates that around 7 million people died as a result of the effects of air pollution in 2012 (WHO, 2014), and it cites air pollution as being one of the world's greatest environmental health risks. Ozone in particular adversely affects human health and agricultural production. Tropospheric ozone has been increasing globally at rates of $0.3-1.0 \mathrm{ppb} \mathrm{yr}^{-1}$ over past few decades in the Northern Hemisphere (Dentener et al., 2010, and references therein). Ozone is formed by sunlight-driven oxidation from ozone precursors such as methane $\left(\mathrm{CH}_{4}\right)$, carbon monoxide (CO), non-methane volatile organic compounds (NMVOCs), and nitrogen oxides $\left(\mathrm{NO}_{x}\right)$ in the troposphere. Monitoring of the amount of the tropospheric ozone is required to understand the current situation and to forecast future ozone amounts.

Ozone plays different roles in different altitude regions in the troposphere. It is well known that ozone at the surface level is a harmful pollutant that has a detrimental effect on the health of people and plants and can significantly reduce crop yields. The lifetime of ozone in the free troposphere ranges from a few days to weeks, so the transport scale of ozone is potentially intercontinental and hemispheric. Upper tropospheric ozone is the third-most important warming gas and is responsible for a large part of the human enhancement of the global greenhouse effect. To further understand these different characteristics of tropospheric ozone, it is important to obtain information on the vertical distribution of ozone separately in the lowermost troposphere (LMT), in the middle troposphere (MT), and in the upper troposphere (UT) on a global scale.

Ozone has been observed from space in various spectral ranges, including the ultraviolet (UV), visible (VIS), thermal infrared (TIR), and microwave (MW), with different observation geometries (nadir down-looking and limb sounding). Observations at different wavelengths have sensitivity to ozone at different altitudes. Generally, nadir down-looking observations in the UV/VIS range are sensitive to ozone in the LMT (e.g., the Ozone Monitoring Instrument, OMI, onboard the Aura satellite: Levelt et al., 2006; and the second Global Ozone Monitoring Experiment, GOME-2, onboard the MetOp satellite: Munro et al., 2006), while nadir downlooking in the TIR range is sensitive to ozone in the MT (e.g., the Thermal Emission Spectrometer, TES, onboard the Aura satellite: Osterman et al., 2008; and the Infrared Atmospheric Sounding Interferometer, IASI, onboard the MetOp satellites: Clerbaux et al., 2009). Limb sounding and stellar/solar occultation is used to sound ozone in the stratosphere and above. Limb sounding in the UV/VIS region sounds ozone in the stratosphere, and stellar occultation instruments observe ozone above the stratosphere (e.g., the Scanning Imaging Absorption Spectrometer for Atmospheric Chartography, SCIAMACHY: Brinksma et al., 2006; and the Global Ozone Monitoring by Occultation of Stars, GOMOS: Kyrölä et al.,
2004; both onboard the Envisat satellite). Limb sounding in the MW spectral range is sensitive at altitudes above the UT (e.g., the Microwave Limb Sounder, MLS, onboard the Aura satellite: Waters et al., 2006; and the Superconducting Submillimeter-Wave Limb-Emission Sounder, SMILES, onboard the International Space Station: Kikuchi et al., 2010).

Measurement using several wavelength ranges is an advanced method of deriving a vertically resolved ozone profile. Ziemke et al. (2006) derived the global distribution of the tropospheric ozone column by subtracting the stratospheric ozone column measured using the MLS MW spectra from the total ozone column measured using the OMI UV spectra. A feasibility study of the tropospheric ozone profile retrieval using the optimal estimation method (OEM; Rodgers, 2000) combining UV and TIR measurements was performed by Landgraf and Hasekamp (2007). Worden et al. (2007) implemented the concept of synergetic retrieval using the OMI and TES measurements. Natraj et al. (2011) showed that retrieval sensitivity in the LMT is improved by combining the UV and TIR measurements. Fu et al. (2013) implemented a synergetic retrieval of boundary layer ozone using UV and TIR spectra measured with the OMI and TES instruments. The degree of freedom for signal (DFS) for ozone from the surface to $700 \mathrm{hPa}$ was estimated to be $0.37 \pm 0.09$ for 22 coincident measurements made using the OMI, the TES, and an ozonesonde from 2004 to 2008 (see Table 2 in Fu et al., 2013). Cuesta et al. (2013) also performed a synergetic retrieval of boundary layer ozone, using the GOME-2 (for UV) and IASI (for TIR) measurements. The DFS values for ozone up to $3 \mathrm{~km}$ were estimated to be $0.34 \pm 0.04$ and $0.23 \pm 0.04$ over land and ocean, respectively, for 1920 August 2009 over Europe (see Table 1 in Cuesta et al., 2013). The corresponding heights of maximum sensitivity were $2.20 \pm 0.50$ and $3.42 \pm 0.59 \mathrm{~km}$. The DFS values were increased by approximately $50 \%$ by combining the GOME- 2 and IASI measurements, compared with the IASI measurement alone. The other approach to retrieve the tropospheric ozone profile, using the neural network technique, was performed with the SCIAMACHY nadir measurements for the UV and VIS ranges (Sellitto et al., 2012a, b). The results demonstrated the effectiveness of combining several wavelength ranges to retrieve the tropospheric ozone profile.

Our idea is to add MW measurements to improve the synergetic retrieval of the tropospheric ozone profile. To the best of our knowledge, no study has attempted to show how MW measurements improve the retrieval of the vertical profile of tropospheric ozone. In this study, we performed a feasibility study of obtaining a vertically resolved ozone amount in the troposphere by using synergetic retrieval from a combination of UV, TIR, and MW measurements covering wide wavelength ranges. This work should be of benefit to future air-quality monitoring missions, such as Air POLLution Observation (APOLLO), Geostationary mission for Meteorology and Air Pollution (GMAP-Asia; Kasai et al., 2011), uvSCOPE (Fujinawa et al., 2015), and air pollution prediction 
project in National Institute of Information and Communication Technology (NICT). The objective of the APOLLO and GMAP-Asia missions is to measure short-lived climate pollutants for monitoring global pollution and climate change. These missions assume atmospheric monitoring from the International Space Station (ISS) and from geostationary orbit, respectively. The uvSCOPE mission, a candidate for the Earth observation section of ISS, aims to detect hotspots of air pollutant with a high horizontal resolution (such as $1 \mathrm{~km} \times 1 \mathrm{~km}$ ) for better understanding of the inventory of air pollution. The target of the NICT air pollution prediction project is to make a health index to aid in the mitigation of air pollution disasters using high horizontal resolution (a scale of a few kilometers) pollution forecasting from multiple data sets, such as satellite observation, ground-based observation, and in situ observation data sets.

In this paper, we report a feasibility study of the tropospheric ozone profile retrieval based on the concept of APOLLO, i.e., utilizing synergetic observations afforded by UV, TIR, and MW instruments to obtain vertically resolved information on tropospheric ozone not only at the boundary layer, but also in the middle and upper troposphere. The major aim of our feasibility study is to evaluate the sensitivity of the tropospheric ozone profile retrieval to the addition of MW measurements to the multi-spectral synergetic retrieval. The simulation was thus performed under ideal conditions for synergetic retrieval of the tropospheric ozone profile.

\section{Observation scenario}

\subsection{Observation wavelength region and geometry}

The observation scenario used in the simulation follows the concept of the APOLLO mission. Three spectrometers in the ISS were assumed to observe the three wavelength ranges: UV, TIR, and MW. Figure 1 shows the observation geometries for the three spectrometers. The UV and TIR instruments used nadir down-looking, and the MW instrument used limb sounding at tangent heights from 10 to $80 \mathrm{~km}$. In this feasibility study, we assumed spherically homogeneous atmosphere along the line of sight of the MW measurement. The height of the ISS was assumed to be $300 \mathrm{~km}$. The azimuthal direction of the field of view of the MW limb sounding was set parallel to the ISS's orbital motion. The tangent point of the MW limb sounding passes the UV and TIR nadir down-looking point approximately $5 \mathrm{~min}$ before the UV and TIR nadir down-looking. The time delay of $5 \mathrm{~min}$ corresponds to approximately $6 \mathrm{~km}$ of travel if a typical value of horizontal wind speed in the troposphere and the stratosphere $\left(1.2 \mathrm{kmmin}^{-1}\right)$ is assumed (Fleming et al., 1988), which is less than the typical horizontal resolution of the MW limb measurement ( $8 \mathrm{~km}$ for Aura/MLS: Waters et al., 2006). Therefore, we ignored this time difference between the UV and TIR measurements and MW measurement. Table 1 sum-

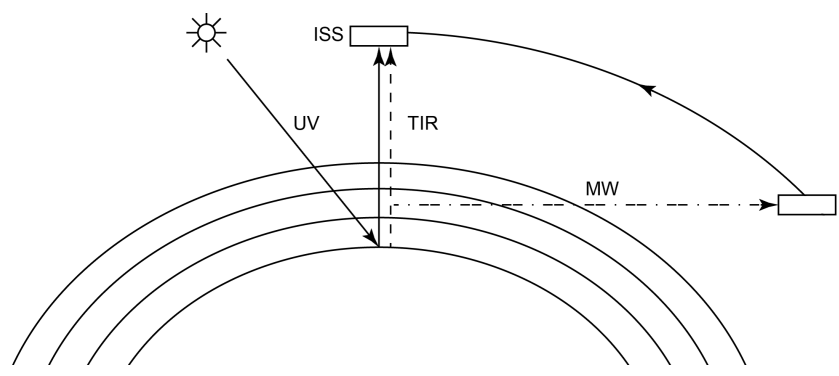

Figure 1. Geometries used for observation: nadir (UV and TIR) and $\operatorname{limb}(\mathrm{MW})$.

marizes the specifications of the three instruments and the three radiative transfer models.

The wavelength range for the UV measurement was set to $305-340 \mathrm{~nm}$. UV wavelength range shorter than $305 \mathrm{~nm}$ is useful for the stratospheric ozone profile retrieval (e.g., Bak et al., 2012). We added the MW limb measurement which is more sensitive to stratospheric ozone. We excluded the shorter UV wavelength ranges to clearly show whether stratospheric ozone profile retrieval using MW measurement improves the sensitivity of tropospheric ozone profile retrieval. Although there is a benefit of adding VIS wavelengths (340-505 nm; e.g., Sellitto et al., 2012a, b), we decided not to because the wavelength dependence of surface reflectance, the absorption of $\mathrm{NO}_{2}$, and the Ring effect were beyond the scope of this study. The spectral resolution, defined as the full width at half maximum (FWHM), and the sampling step were assumed to be 0.6 and $0.2 \mathrm{~nm}$, respectively. The noise equivalent spectral radiance (NESR) was obtained by dividing the simulated backscattered radiance by the signal-to-noise ratio (SNR). We used SNR values of the APOLLO instrument setups in the UV simulation. Three references of the SNR value were prepared for high, middle, and low level of the radiance. The SNR value for the simulated radiance was linearly interpolated by two of three reference SNR values. Table 2 shows the reference SNR values at 305 and $340 \mathrm{~nm}$, and the solar zenith angle (SZA) and surface albedo of the three conditions (Private communication with $\mathrm{K}$. Gerilowski). The values of SNR used in the UV simulation were estimated to be approximately 90 and 1400 at 305 and $340 \mathrm{~nm}$, respectively.

We assumed that the nadir-viewing TIR instrument was a Fourier transform spectrometer covering the TIR spectral range (980-1080 $\left.\mathrm{cm}^{-1}\right)$ including the ozone $\mathrm{v} 3$ absorption band, $9.6 \mu \mathrm{m}\left(1045 \mathrm{~cm}^{-1}\right)$, as the TES instrument (Osterman et al., 2008) and the IASI instrument (Clerbaux et al., 2009). We set the maximum optical path difference to $8.33 \mathrm{~cm}$, which corresponds to a spectral resolution of $0.12 \mathrm{~cm}^{-1}$ and calculated the noise equivalent differential temperature for each wavelength, assuming that the SNR is a constant value of 300 over the entire spectral range. 
Table 1. Specifications of three assumed instruments and radiative transfer models.

\begin{tabular}{llll}
\hline & UV & TIR & MW \\
\hline Observation geometry & nadir-viewing & nadir-viewing & limb-viewing \\
Wavelength & $305-340 \mathrm{~nm}$ & $980-1080 \mathrm{~cm}^{-1}$ & $345-357 \mathrm{GHz}, 639-651 \mathrm{GHz}$ \\
Spectral resolution & $0.6 \mathrm{~nm}$ & $\sim 0.12 \mathrm{~cm}^{-1}$ & $25 \mathrm{MHz}$ \\
Sampling step & $0.2 \mathrm{~nm}$ & $\sim 0.12 \mathrm{~cm}^{-1}$ & $25 \mathrm{MHz}$ \\
Sensitivity* & $90(305 \mathrm{~nm})-1400(340 \mathrm{~nm})$ & 300 & $0.7 \mathrm{~K}(350 \mathrm{GHz}$ band $), 1.7 \mathrm{~K}(645 \mathrm{GHz}$ band $)$ \\
Scattering & yes & no & no \\
Emission & no & yes & yes \\
Forward model & SCIATRAN & LBLRTM & AMATERASU \\
\hline
\end{tabular}

* Instrument sensitivity is described in the way commonly used for each spectral region: SNR for UV and TIR and noise equivalent brightness temperature for MW.

Table 2. Estimation of three reference SNR values in the UV simulation.

\begin{tabular}{lrr}
\hline & SNR at 305 nm & SNR at 340 nm \\
\hline Case 1: high-level radiance (albedo 90\%, SZA 0 ${ }^{\circ}$ & $\sim 200$ & $\sim 2550$ \\
Case 2: middle-level radiance (albedo 25\%, SZA 45 $5^{\circ}$ & $\sim 60$ & $\sim 1200$ \\
Case 3: low-level radiance (albedo 5\%, SZA 80 $)$ & $\sim 10$ & $\sim 450$ \\
\hline
\end{tabular}

Several ozone transitions in the microwave/sub-millimeter range have been employed by recent spaceborne instruments, e.g., 206.1 and $235.7 \mathrm{GHz}$ for Aura/MLS (Waters et al., 2006), 501.8 and $544.6 \mathrm{GHz}$ for Odin/SMR (Urban et al., 2005), and $625.4 \mathrm{GHz}$ for Aura/MLS and JEM/SMILES (Kikuchi et al., 2010). The assumed MW limb-sounding instrument covered two frequency bands: $350 \mathrm{GHz}$ (345$357 \mathrm{GHz})$ and $645 \mathrm{GHz}(639-651 \mathrm{GHz})$. There are ozone lines at $352.3,352.8$, and $355.0 \mathrm{GHz}$ in the former and at $640.1,642.3,644.8,645.6,647.8$, and $650.7 \mathrm{GHz}$ in the latter. These frequency bands were selected for detection of not only ozone but also of other molecules related to global warming and air pollution $\left(\mathrm{H}_{2} \mathrm{O}, \mathrm{CO}, \mathrm{CH}_{3} \mathrm{CN}, \mathrm{N}_{2} \mathrm{O}, \mathrm{SO}_{2}\right.$, $\mathrm{H}_{2} \mathrm{CO}$, and $\mathrm{HNO}_{3}$ ). The channel separation width of the spectrometer was assumed to be $25 \mathrm{MHz}$. The frequency resolution, defined by FWHM was set to be identical to the channel separation width. The antenna diameter was assumed to be $40 \mathrm{~cm}$. The Earth's limb was assumed to be scanned vertically from 10 to $80 \mathrm{~km}$ with an interval of $2 \mathrm{~km}$ and total of 35 spectra were acquired in one vertical limb scan. We assumed that the typical integration time was $0.5 \mathrm{~s}$ for one spectrum accumulation and that it took $17.5 \mathrm{~s}$ for one vertical limb scan. The brightness temperature noise was estimated to be 0.7 and $1.7 \mathrm{~K}$ for the 350 and $645 \mathrm{GHz}$ bands, respectively, assuming the system noise temperature of a typical Schottky barrier mixer $(2500$ and $6000 \mathrm{~K}$ for the 350 and $645 \mathrm{GHz}$ bands, respectively).

\subsection{Atmospheric conditions}

We used typical atmospheric scenarios in summer and winter for East Asia, which is one of most ozone-polluted regions and a major source of the intercontinental transport of ozone toward North America. We chose two observation points in East Asia, $35^{\circ} \mathrm{N}, 116.5^{\circ} \mathrm{E}$ (central-east China, CEC, located between Beijing and Shanghai) and $31^{\circ} \mathrm{N}, 127.25^{\circ} \mathrm{E}$ (East China Sea, ECS, centered among China, Japan, South Korea, and Taiwan). The CEC is the area where largest amount of boundary layer ozone was observed from the Aura/OMI measurement (Hayashida et al., 2015). The ECS was chosen for a comparison of urban area and ocean. We selected June and December for representatives of summer and winter seasons, respectively. Hayashida et al. (2015) reported that the amount of the boundary layer ozone in the area near CEC was maximized in June and minimized in December. The observation time was set to 04:00 GMT, which corresponds to 11:46 and 12:29 for CEC and ECS local times, respectively. The local times around noon were set because ozone profile retrieval sensitivity is apparently higher when the solar zenith angle (SZA) is low or moderate, as shown in a simulation study by Landgraf and Hasekamp (2007).

We made a total of 20 atmospheric scenarios, as shown in Table 3. The vertical profiles of ozone, temperature, and water vapor are shown in Fig. 2. Of the four cases (CEC in June, ECS in June, CEC in December, and ECS in December), the ozone partial column (PC) in the LMT was the largest (approximately $5 \times 10^{21} \mathrm{~m}^{-2}$ ) for CEC in June and was the smallest (approximately $2 \times 10^{21} \mathrm{~m}^{-2}$ ) for CEC in December.

We interpolated the values of ozone, temperature, and water vapor from the following three original atmospheric profiles by using cubic splines to make the atmospheric profile smooth in the overlapping regions for a vertical pressure $(p)$ 
Table 3. Summary of 20 atmospheric scenarios used in the simulation.

\begin{tabular}{|c|c|c|c|c|c|c|c|c|}
\hline No. & Date $^{a}$ & Area $^{b}$ & $T_{\mathrm{S}}^{\mathrm{c}}(\mathrm{K})$ & $P_{\mathrm{S}}^{\mathrm{c}}(\mathrm{hPa})$ & $\mathrm{PC}(\mathrm{UT})^{\mathrm{d}}\left(\mathrm{m}^{-2}\right)$ & $\mathrm{PC}(\mathrm{MT})^{\mathrm{d}}\left(\mathrm{m}^{-2}\right)$ & $\mathrm{PC}(\mathrm{LMT})^{\mathrm{d}}\left(\mathrm{m}^{-2}\right)$ & $\mathrm{H}_{2} \mathrm{O}^{\mathrm{e}}\left(\mathrm{g} \mathrm{cm}^{-2}\right)$ \\
\hline 01 & $6 / 16$ & CEC & 301.4 & 976.0 & $2.57 \times 10^{21}$ & $5.87 \times 10^{21}$ & $5.66 \times 10^{21}$ & 3.4 \\
\hline 02 & $6 / 24$ & CEC & 304.5 & 970.2 & $4.13 \times 10^{21}$ & $6.14 \times 10^{21}$ & $4.51 \times 10^{21}$ & 2.1 \\
\hline 03 & $6 / 25$ & CEC & 305.0 & 970.2 & $3.65 \times 10^{21}$ & $6.52 \times 10^{21}$ & $4.93 \times 10^{21}$ & 2.3 \\
\hline 04 & $6 / 3$ & ECS & 293.9 & 999.6 & $1.49 \times 10^{21}$ & $4.39 \times 10^{21}$ & $3.72 \times 10^{21}$ & 4.5 \\
\hline 05 & $6 / 9$ & ECS & 294.9 & 1010.9 & $1.68 \times 10^{21}$ & $4.17 \times 10^{21}$ & $3.96 \times 10^{21}$ & 4.2 \\
\hline 06 & $6 / 20$ & ECS & 296.0 & 1004.2 & $2.92 \times 10^{21}$ & $6.34 \times 10^{21}$ & $1.86 \times 10^{21}$ & 3.7 \\
\hline 07 & $6 / 21$ & ECS & 296.5 & 1002.9 & $3.00 \times 10^{21}$ & $4.26 \times 10^{21}$ & $2.39 \times 10^{21}$ & 6.0 \\
\hline 08 & $6 / 26$ & ECS & 296.8 & 1010.0 & $3.27 \times 10^{21}$ & $6.20 \times 10^{21}$ & $2.25 \times 10^{21}$ & 4.1 \\
\hline 09 & $6 / 27$ & ECS & 297.6 & 1006.6 & $2.13 \times 10^{21}$ & $3.13 \times 10^{21}$ & $1.49 \times 10^{21}$ & 6.0 \\
\hline 10 & $6 / 30$ & ECS & 298.1 & 1004.5 & $2.71 \times 10^{21}$ & $3.05 \times 10^{21}$ & $1.80 \times 10^{21}$ & 5.9 \\
\hline 11 & $12 / 2$ & CEC & 280.7 & 993.1 & $3.20 \times 10^{21}$ & $4.47 \times 10^{21}$ & $1.83 \times 10^{21}$ & 1.1 \\
\hline 12 & $12 / 11$ & CEC & 280.0 & 988.8 & $2.66 \times 10^{21}$ & $4.38 \times 10^{21}$ & $2.10 \times 10^{21}$ & 1.4 \\
\hline 13 & $12 / 20$ & CEC & 271.6 & 997.3 & $4.58 \times 10^{21}$ & $4.14 \times 10^{21}$ & $2.22 \times 10^{21}$ & 0.3 \\
\hline 14 & $12 / 22$ & CEC & 278.1 & 985.9 & $4.25 \times 10^{21}$ & $4.27 \times 10^{21}$ & $2.21 \times 10^{21}$ & 0.6 \\
\hline 15 & $12 / 27$ & CEC & 271.3 & 992.6 & $4.51 \times 10^{21}$ & $4.41 \times 10^{21}$ & $2.10 \times 10^{21}$ & 0.4 \\
\hline 16 & $12 / 28$ & CEC & 274.0 & 985.8 & $4.12 \times 10^{21}$ & $4.33 \times 10^{21}$ & $2.15 \times 10^{21}$ & 0.4 \\
\hline 17 & $12 / 4$ & ECS & 286.7 & 1019.2 & $4.04 \times 10^{21}$ & $4.48 \times 10^{21}$ & $2.54 \times 10^{21}$ & 1.1 \\
\hline 18 & $12 / 12$ & ECS & 287.9 & 1019.9 & $2.35 \times 10^{21}$ & $4.81 \times 10^{21}$ & $2.92 \times 10^{21}$ & 2.0 \\
\hline 19 & $12 / 21$ & ECS & 282.4 & 1025.7 & $4.91 \times 10^{21}$ & $4.74 \times 10^{21}$ & $2.68 \times 10^{21}$ & 0.8 \\
\hline 20 & $12 / 26$ & ECS & 281.3 & 1019.3 & $3.72 \times 10^{21}$ & $4.38 \times 10^{21}$ & $2.68 \times 10^{21}$ & 0.9 \\
\hline
\end{tabular}

a All simulation data are from 2009. ${ }^{\mathrm{b}} \mathrm{CEC}$ and ECS stand for central-east China $\left(30-40^{\circ} \mathrm{N}, 110-123^{\circ} \mathrm{E}\right)$ and the East China Sea $\left(29-33^{\circ} \mathrm{N}, 125-129.5^{\circ} \mathrm{E}\right)$, respectively. ${ }^{\mathrm{c}}$ Temperature and pressure at the surface. ${ }^{\mathrm{d}} \mathrm{PC}$ means ozone partial column. PC is presented for each altitude region: upper troposphere (UT, 215-383 hPa), middle troposphere (MT, 383-749 hPa), and lowermost troposphere (LMT, > $749 \mathrm{hPa}$ ). ${ }^{\mathrm{e}} \mathrm{H}_{2} \mathrm{O}$ column amount in the troposphere.

grid defined as follows.

$p[i]= \begin{cases}10^{3-(i+1) / 24}[\mathrm{hPa}] & i=1,2, \ldots, 71(\geq 1 \mathrm{hPa}) \\ 10^{3-(i-35) / 12}[\mathrm{hPa}] & i=72,73, \ldots, 108(<1 \mathrm{hPa})\end{cases}$

The scale height of the vertical profiles that we used was $3 \mathrm{~km}$.

The profiles of ozone, temperature, and water vapor in the vertical region from the surface to $65 \mathrm{hPa}$ (approximately $20 \mathrm{~km}$ ) were simulated by a one-way nested global-regional air quality forecasting (AQF) system (Takigawa et al., 2007, 2009). This system is based on the CHASER (Chemical Atmospheric General Circulation model for the Study of Atmospheric Environment and Radiative Forcing) model (Sudo et al., 2002) and the WRF (Weather Research and Forecasting)/Chem model (Grell et al., 2005) version 3.3. The horizontal resolution of this system is approximately $40 \mathrm{~km}$. The profiles over CEC and ECS were spatially averaged for the periods of 1 to 30 June and 1 to 31 December, 2009. The surface temperature was simulated with the AQF system; the temperature difference between the surface and the lower boundary of the lowest atmospheric layer was less than $1 \mathrm{~K}$. We set the surface temperature equal to the value at surface pressure since the effect of the temperature contrast between the atmosphere and surface is large for the TIR measurement.

The profiles (ozone, temperature, and water vapor) for the 985-0.01 hPa vertical range were taken from the Modern
Era Retrospective-Analysis for Research and Applications (MERRA) data (Rienecker et al., 2011). The MERRA DAS 3d analyzed state (inst6_3d_ana_Nv) data product provided three-dimensional fields for layer pressure thickness, air temperature, specific humidity, and ozone mixing ratio at $6 \mathrm{~h}$ intervals (00:00, 06:00, 12:00, 18:00 GMT). The MERRA data covered a $0.66^{\circ} \times 0.5^{\circ}$ latitude-longitude grid. We averaged the MERRA data at 06:00 GMT (the closest local time of 12:00 LT in CEC and ECS) on the same date of the selected $\mathrm{AQF}$ system profiles for each region (CEC and ECS). No interpolation for local time was performed on the MERRA data.

The temperature data of the COSPAR International Reference Atmosphere (CIRA) model (Fleming et al., 1990) was used above the vertical level of $0.01 \mathrm{hPa}$. The CIRA-86 model includes monthly and zonally mean temperatures and pressures $(0-120 \mathrm{~km})$ with almost global coverage $\left(80^{\circ} \mathrm{N}-\right.$ $80^{\circ} \mathrm{S}$ ) at an interval of $10^{\circ}$. We averaged the two temperature data sets at 30 and $40^{\circ} \mathrm{N}$ for CEC, and used the temperature data at $30^{\circ} \mathrm{N}$ for ECS. The mixing ratios of ozone and water vapor at pressures less than $0.01 \mathrm{hPa}$ were assumed to be equal to those at the upper boundary $(0.01 \mathrm{hPa})$ of the MERRA data due to the lack of appropriate reference data. We confirmed that the effects of the assumption for the upper vertical range were negligibly small for our calculation.

We assumed the following quasi-clear sky cases for all scenarios. No-cloud conditions were considered for all wave- 
(a)

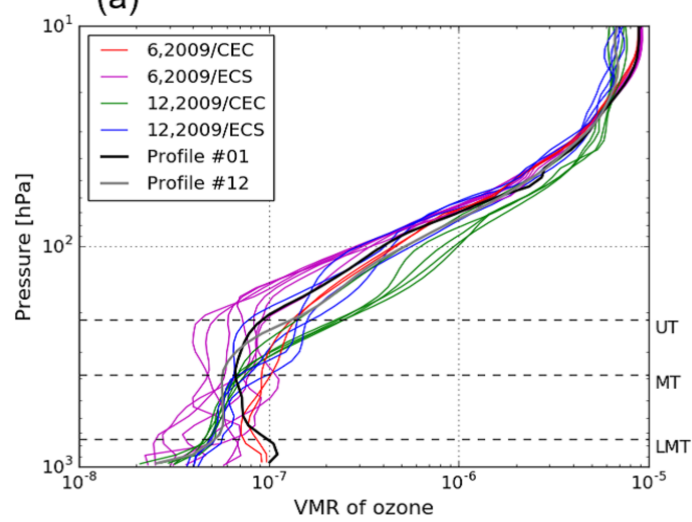

(b)

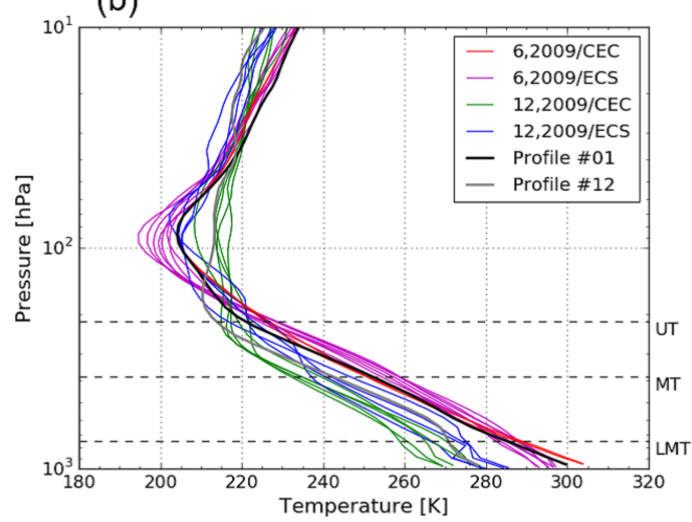

(c)

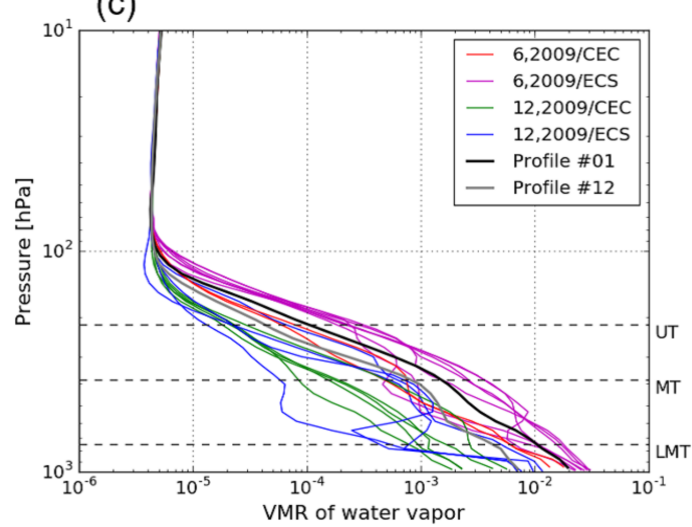

Figure 2. Twenty atmospheric scenarios used in this study: (a) VMR of ozone, (b) temperature, and (c) VMR of water vapor. They are divided into four groups, as denoted by color: CEC in June 2009 (red), ECS in June 2009 (purple), CEC in December 2009 (green), and ECS in December 2009 (blue). Two example profiles (nos. 01 and 12, black and gray lines, respectively) were used to obtain results shown in Figs. 5 and 6.

length ranges. Basic background aerosol was taken into account only in the UV calculation. The aerosol profile was included as a known parameter because it was reported that the inclusion of aerosol profile changed within $2 \%$ of the LMT ozone amount in the case of the Aura/OMI measure- ment (Hayashida et al., 2015). We used the vertical profiles of urban and maritime aerosols of a standard mixing state as described by Hess et al. (1998). These profiles were adjusted to be 0.2 of the total optical thicknesses of the aerosols (moderate pollution). The aerosol profile was not included in the TIR calculation because the extinction of radiation due to aerosol particles with a scale of approximately $9.6 \mu \mathrm{m}$, which corresponds to the wavelength of the TIR range, is negligibly small for the synergetic retrieval of the LMT ozone with the TIR measurement (e.g., Natraj et al., 2011). We assumed that surface albedo was constant in the target UV range (305$340 \mathrm{~nm}$ ). The information on surface albedo for simulating UV radiance spectra was taken from the database described by Kleipool et al. (2008). This database contains the monthly global maps of the Earth's surface Lambertian equivalent reflectance (LER) deduced from the Aura/OMI measurements. We obtained monthly and spatially averaged albedo values of 0.056 (June) and 0.063 (December) for CEC and 0.065 (June) and 0.084 (December) for ECS, respectively, from the LER data at the wavelength of $328.1 \mathrm{~nm}$, which is the shortest wavelength in the database. The effect of the uncertainty of the UV surface albedo on tropospheric ozone measurements from space was discussed by Noguchi et al. (2014). The surface emissivity for modeling the TIR radiance spectra was estimated by linear regression analysis based on the Advanced Spaceborne Thermal Emission and Reflection Radiometer (ASTER) Spectral Library (Baldridge et al., 2009). The surface emissivity for the MW measurement was set to 1.0 for the entire range. MW limb measurements are generally insensitive to the surface emissivity since the atmosphere is strongly opaque in this wavelength range.

\section{Synergetic retrieval simulation}

\subsection{Forward models of UV, TIR, and MW regions}

We used the SCIATRAN radiative transfer model version 3.1 (Rozanov et al., 2005), the Line-By-Line Radiative Transfer Model (LBLRTM) version 12.1 (Clough et al., 2005), and the Advanced Model for Atmospheric Terahertz Radiation Analysis and Simulation (AMATERASU; Baron et al., 2008) for the calculation of spectra in the UV, TIR, and MW wavelength ranges, respectively. To investigate the potential advantage of including MW observations in the retrieval of the tropospheric ozone profile, we assumed no bias between the three forward models.

The SCIATRAN model was developed by the Institute of Remote Sensing/Institute of Environmental Physics (IFE/IUP) of the University of Bremen, Germany, for fast and precise simulation of radiance spectra in the UV, VIS, and near-infrared ranges as measured by spaceborne instruments, e.g., GOME (240-790 nm) and SCIAMACHY (240$2400 \mathrm{~nm}$ ). SCIATRAN is applicable to spectral regions ranging from 175.44 to $2400 \mathrm{~nm}$, and is basically compatible 
with arbitrary observation geometries and sensor positions in space, in the atmosphere, and on the ground. The spherical shape of the Earth's atmosphere, including the refraction effect, is properly taken into account when simulating the radiance spectra.

The LBLRTM model is an accurate and efficient line-byline radiative transfer model and has been extensively validated for atmospheric radiance spectra ranging from UV to sub-millimeter wavelengths. The line-by-line calculation of the optical thickness of the atmospheric layers is conducted on the basis of the spectroscopic line parameter database (HITRAN 2008) with its updates (Rothman et al., 2009). This model is used as the forward model in retrieval algorithms for analyzing spaceborne measurements such as EOS-Aura/TES (Clough et al., 2006) and GOSAT/TANSO-FTS (Saitoh et al., 2009).

The AMATERASU model consists of a line-by-line radiative transfer calculation allowing for a multi-layered horizontally homogeneous shell atmosphere. This model has been implemented in the retrieval analysis of the SMILES measurements (e.g., Baron et al., 2011) and in the feasibility study of a sub-millimeter instrument for planetary science (Kasai et al., 2012). The spectroscopic parameters were from commonly used databases such as the HITRAN 2008 molecular spectroscopic database (Rothman et al., 2009) and the JPL spectroscopic catalog (Pickett et al., 1998). The continuum absorption due to dry and wet air was taken into account; it is based on the formulation in Pardo et al. (2001).

\subsection{Theoretical retrieval basis and error estimation}

The OEM (Rodgers, 2000) was used for the synergetic retrieval and error estimation. The retrieved state vector $\hat{\boldsymbol{x}}$ was estimated by minimizing the differences between the observed radiance spectra $\boldsymbol{y}_{\mathrm{obs}}$ and the modeled radiance spectra $\boldsymbol{y}_{\text {mod }}$, using a constraint from an a priori state vector $\boldsymbol{x}_{\mathrm{a}}$.

$\hat{\boldsymbol{x}}=\mathbf{A} \boldsymbol{x}+(\mathbf{I}-\mathbf{A}) \boldsymbol{x}_{\mathrm{a}}+\mathbf{G} \boldsymbol{\epsilon}$

In this equation, $\boldsymbol{x}$ is the true state vector, $\mathbf{A}$ is the averaging kernel matrix, $\mathbf{G}$ is the gain (contribution function) matrix, and $\boldsymbol{\epsilon}$ is the measurement noise vector. The averaging kernel matrix characterizing the sensitivity of the retrieved state vector $\hat{x}$ to the true state vector $\boldsymbol{x}$ is given by

$\mathbf{A}=\frac{\partial \hat{\boldsymbol{x}}}{\partial \boldsymbol{x}}=\mathbf{G K}=\left(\mathbf{K}^{\mathrm{T}} \mathbf{S}_{\epsilon}^{-1} \mathbf{K}+\mathbf{S}_{\mathrm{a}}^{-1}\right)^{-1} \mathbf{K}^{\mathrm{T}} \mathbf{S}_{\epsilon}^{-1} \mathbf{K}$,

where $\mathbf{S}_{\mathrm{a}}$ and $\mathbf{S}_{\epsilon}$ are the a priori covariance matrix and the measurement error covariance matrix, respectively. $\mathbf{K}$ is a weighting function matrix $\left(\mathbf{K}=\partial \boldsymbol{y}_{\bmod } / \partial \boldsymbol{x}\right)$. $\mathbf{A}$ corresponds to the identity matrix when the retrieved profile is equal to the true atmospheric profile. The number of state vector elements that are independently resolved is obtained by summing the diagonal elements of $\mathbf{A}$, and is defined as DFS. The $i$ th element of measurement response vector, $\boldsymbol{m}[\boldsymbol{i}]$, is defined as

$\boldsymbol{m}[i]=\sum_{j} \mathbf{A}[i, j]$.

A value of the measurement response element near unity indicates that almost all information in the retrieval result comes from the observation spectra, while a small value indicates that the retrieval result is largely affected by the a priori.

The total retrieval error covariance $\hat{\mathbf{S}}$ is calculated using the covariance matrices of the smoothing error $\mathbf{S}_{\mathrm{s}}$ and measurement noise $\mathbf{S}_{\mathrm{m}}$.

$$
\begin{aligned}
\hat{\mathbf{S}} & =\mathbf{S}_{\mathrm{s}}+\mathbf{S}_{\mathrm{m}} \\
& =(\mathbf{I}-\mathbf{A}) \mathbf{S}_{\mathrm{a}}(\mathbf{I}-\mathbf{A})^{\mathrm{T}}+\mathbf{G} \mathbf{S}_{\epsilon} \mathbf{G}^{\mathrm{T}} \\
& =\left(\mathbf{K}^{\mathrm{T}} \mathbf{S}_{\epsilon}^{-1} \mathbf{K}+\mathbf{S}_{\mathrm{a}}^{-1}\right)^{-1}
\end{aligned}
$$

The square root of the $\hat{\mathbf{S}}$ diagonals is the total retrieval error in $\hat{\boldsymbol{x}}\left(\boldsymbol{\epsilon}_{x}\right)$. The value of $\boldsymbol{\epsilon}_{\boldsymbol{x}}$ at the $i$ th layer is given by

$\boldsymbol{\epsilon}_{x}[i]=\sqrt{\hat{\mathbf{S}}[i, i]}$.

We evaluated the sensitivity of the vertical profile of ozone from the synergetic retrieval for seven different combinations of the wavelength ranges, i.e., UV, TIR, MW, TIR + MW, $\mathrm{UV}+\mathrm{MW}$, UV + TIR, and UV + TIR + MW, in the 20 atmospheric scenarios. The state vectors $\boldsymbol{x}, \hat{\boldsymbol{x}}$, and $\boldsymbol{x}_{\mathrm{a}}$ were calculated using logarithm units of the volume mixing ratio (VMR). The diagonal components of $\mathbf{S}_{\mathrm{a}}$ were the squares of the a priori error $\sigma_{\mathrm{a}}$ at each vertical pressure grid. The value of $\sigma_{\mathrm{a}}$ was set to $100 \%$ of the log-based a priori VMR to simply quantify the error reduction from the error in the a priori error to the error in the retrieved state. The offdiagonal components in $\mathbf{S}_{\mathrm{a}}$ indicate the correlations between the ozone concentrations in different vertical layers. The nonzero off-diagonal components in $\mathbf{S}_{\mathrm{a}}$ facilitate retrieval of the ozone concentration using the correlations between contiguous other layers (e.g., Saitoh et al., 2009). We set the off-diagonal components in $\mathbf{S}_{\mathrm{a}}$ to zero to avoid improvement from the ozone profile retrieval through the correlations between different vertical layers. The diagonal components of $\mathbf{S}_{\epsilon}$ were the squares of the measurement error $\sigma_{\epsilon}$. The offdiagonal components of $\mathbf{S}_{\epsilon}$ were set to zero.

We normalized the state vector $\boldsymbol{x}$ and measurement vector $\boldsymbol{y}$ with $\boldsymbol{\sigma}_{\mathrm{a}}$ and $\sigma_{\epsilon}$ because having values of different orders in a vector and a matrix often causes undesirable mathematical errors.

$\boldsymbol{u}=\frac{\boldsymbol{x}-\boldsymbol{x}_{\mathrm{a}}}{\boldsymbol{\sigma}_{\mathrm{a}}}$

$\boldsymbol{v}=\frac{\boldsymbol{y}_{\mathrm{obs}}-\boldsymbol{y}_{\mathrm{mod}}}{\sigma_{\epsilon}}$

The normalized weighting function is given by

$\mathbf{K}^{\prime}=\mathbf{K D}\left(\sigma_{\mathrm{a}} / \sigma_{\epsilon}\right)$. 
Here, $\mathbf{D}(\boldsymbol{a})$ is a diagonal matrix in which the diagonal elements are equal to the components of the vector $\boldsymbol{a} . \mathbf{S}_{\mathrm{a}}$ and $\mathbf{S}_{\epsilon}$ were normalized in the same way.

$\mathbf{S}_{\mathrm{a}}^{\prime}=\mathbf{D}\left(1 / \boldsymbol{\sigma}_{\mathrm{a}}\right) \mathbf{S}_{\mathrm{a}} \mathbf{D}\left(1 / \boldsymbol{\sigma}_{\mathrm{a}}\right)^{\mathrm{T}}$

$\mathbf{S}_{\epsilon}^{\prime}=\mathbf{D}\left(1 / \sigma_{\epsilon}\right) \mathbf{S}_{\epsilon} \mathbf{D}\left(1 / \sigma_{\epsilon}\right)^{\mathrm{T}}$

$\mathbf{A}$ and $\hat{\mathbf{S}}$ are expressed using the normalized vectors and matrices as

$$
\begin{aligned}
& \mathbf{A}^{\prime}=\left(\mathbf{K}^{\prime \mathrm{T}} \mathbf{S}_{\epsilon}^{\prime-1} \mathbf{K}^{\prime}+\mathbf{S}_{\mathrm{a}}^{-1}\right)^{-1} \mathbf{K}^{\prime \mathrm{T}} \mathbf{S}_{\epsilon}^{\prime-1} \mathbf{K}^{\prime}, \\
& \hat{\mathbf{S}}^{\prime}=\left(\mathbf{K}^{\prime \mathrm{T}} \mathbf{S}_{\epsilon}^{\prime-1} \mathbf{K}^{\prime}+\mathbf{S}_{\mathrm{a}}^{\prime-1}\right)^{-1} .
\end{aligned}
$$

We evaluated the sensitivity of ozone profile retrieval for seven wavelength combinations in terms of DFS. We calculated the DFS values for the partial column in the UT, MT, and LMT regions. The value of DFS from the $i_{\text {min }}$ th vertical layer to the $i_{\max }$ th layer is given by

$\mathrm{DFS}=\sum_{i=i_{\min }}^{i_{\max }} \mathbf{A}[i, i]$

We also evaluated the sensitivity of ozone profile retrieval using the pressure of maximum sensitivity (PMS) and the reduction rate of error (RRE) for the partial column. The PMS was defined as the pressure of the maximum of the sum of rows of the corresponding $\mathbf{A}$ for the ozone partial column. The RRE is given by

$\mathrm{RRE}=\frac{\mathrm{PCE}_{\mathrm{a} \text { priori }}-\mathrm{PCE}_{\text {retrieved }}}{\mathrm{PCE}_{\mathrm{a} \text { priori }}} \quad[\%]$,

where $\mathrm{PCE}_{\mathrm{a}}$ priori and $\mathrm{PCE}_{\text {retrieved }}$ are the partial column error, PCE, for the a priori state and the retrieved state, respectively. PC represents the partial column of ozone, and the value of PC from the $i_{\min }$ th vertical layer to the $i_{\max }$ th layer is given by

$\mathrm{PC}=\sum_{i=i_{\min }}^{i_{\max }} \frac{p[i] \cdot \mathrm{VMR}[i]}{k_{\mathrm{B}} \cdot T[i]} \Delta z[i]$.

Here, $p[i]$, VMR $[i], T[i]$, and $\Delta z[i]$ are pressure, VMR of ozone, temperature, and the vertical length of the $i$ th layer, respectively. $k_{\mathrm{B}}$ is the Boltzmann constant. The PCE is given by

$\mathrm{PCE}=\sum_{i=i_{\min }}^{i_{\max }} \frac{p[i] \cdot \epsilon_{\mathrm{VMR}}[i]}{k_{\mathrm{B}} \cdot T[i]} \Delta z[i]$

$\epsilon_{\mathrm{VMR}}[i]$ is the total retrieval error in the ozone VMR at the $i$ th layer $\left(\boldsymbol{\sigma}_{\mathrm{a}}\right.$ for PCE $\mathrm{E}_{\mathrm{a} \text { priori }}$ and $\boldsymbol{\epsilon}_{\boldsymbol{x}}$ for $\left.\mathrm{PCE}_{\text {retrieved }}\right)$.
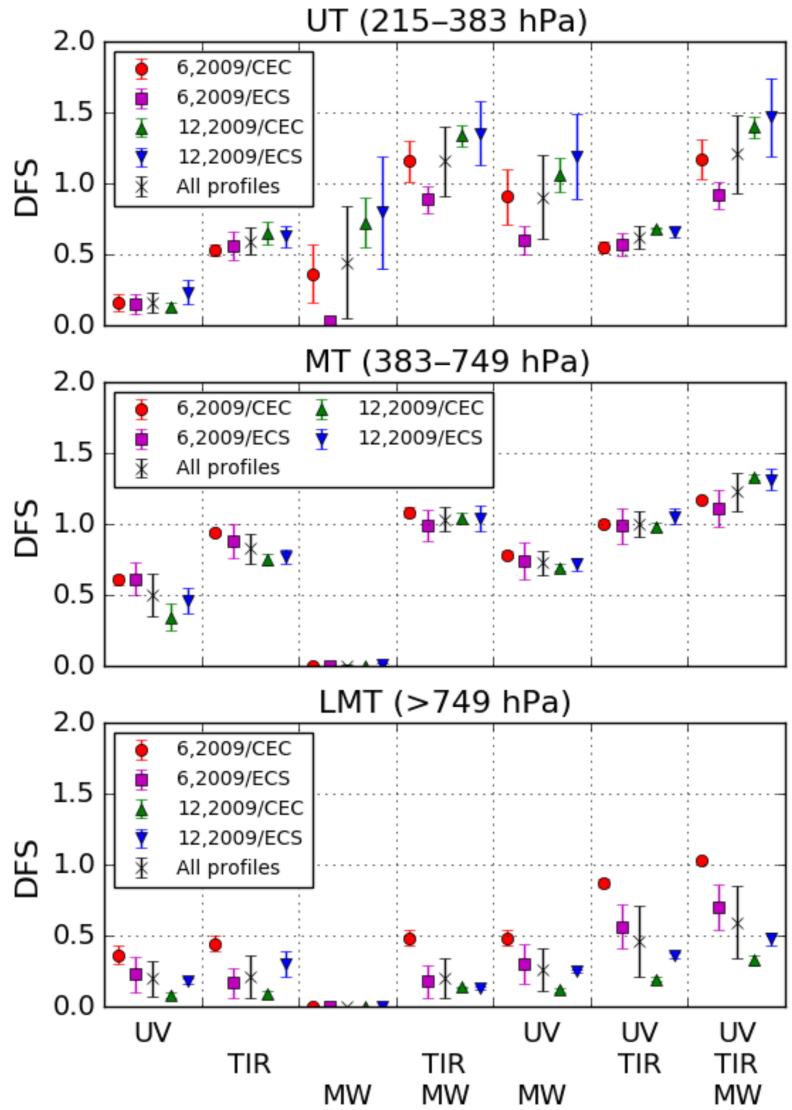

Figure 3. Values of DFS for upper troposphere (UT, 215-383 hPa), middle troposphere (MT, 383-749 hPa), and lowermost troposphere (LMT, > 749 hPa): CEC in June 2009 (red), ECS in June 2009 (purple), CEC in December 2009 (green), ECS in December 2009 (blue), and 20 profiles averaged (black).

\section{Results and discussion}

The sensitivities of ozone profile retrieval in terms of DFS (calculated using Eq. 13) are plotted in Fig. 3 and summarized in Table 4. The average DFS values are plotted in red for CEC in June, in purple for ECS in June, in green for CEC in December, in blue for ECS in December, and in black for all 20 profiles. The error bars represent the standard deviation.

The DFS values in the UT region averaged for all 20 profiles were calculated to be $0.16 \pm 0.08,0.59 \pm 0.10$, and $0.44 \pm$ 0.41 for the UV, TIR, and MW wavelength ranges, respectively. None of the average DFS values for any one wavelength range were larger than unity. For multiple-wavelength measurement, the DFS values increased to $1.15 \pm 0.25$, $0.90 \pm 0.30,0.62 \pm 0.08$, and $1.21 \pm 0.28$, for the TIR + MW, $\mathrm{UV}+\mathrm{MW}, \mathrm{UV}+\mathrm{TIR}$, and UV + TIR + MW measurement combinations, respectively. The DFS for the UV + TIR combination was the lowest among the four multiple-wavelength measurements; adding the MW measurement approximately 
Table 4. Mean and standard deviation ( $1 \sigma)$ of DFS in the upper troposphere (UT, 215-383 hPa), middle troposphere (MT, 383-749 hPa), and lowermost troposphere $(\mathrm{LMT},>749 \mathrm{hPa})$. Standard deviation is shown in parentheses. For example, $0.16(6)$ represents a mean value of 0.16 and a standard deviation of 0.06. Dates are shown in MM, YYYY format.

\begin{tabular}{|c|c|c|c|c|c|c|c|c|}
\hline & & UV & TIR & MW & $\mathrm{TIR}+\mathrm{MW}$ & $\mathrm{UV}+\mathrm{MW}$ & $\mathrm{UV}+\mathrm{TIR}$ & $\mathrm{UV}+\mathrm{TIR}+\mathrm{MW}$ \\
\hline \multirow{3}{*}{$6,2009 / \mathrm{CEC}$} & UT & $0.16(6)$ & $0.53(4)$ & $0.36(20)$ & $1.16(14)$ & $0.91(20)$ & $0.55(4)$ & $1.17(14)$ \\
\hline & MT & $0.61(3)$ & $0.94(2)$ & $<0.01$ & $1.08(4)$ & $0.78(3)$ & $1.00(2)$ & $1.17(1)$ \\
\hline & LMT & $0.37(6)$ & $0.44(6)$ & $<0.01$ & $0.48(6)$ & $0.48(5)$ & $0.87(3)$ & $1.03(1)$ \\
\hline \multirow{3}{*}{$6,2009 / \mathrm{ECS}$} & UT & $0.15(7)$ & $0.56(10)$ & $0.03(3)$ & $0.89(9)$ & $0.60(10)$ & $0.57(8)$ & $0.92(10)$ \\
\hline & MT & $0.61(11)$ & $0.88(12)$ & $<0.01$ & $0.99(11)$ & $0.74(13)$ & $0.99(13)$ & $1.11(13)$ \\
\hline & LMT & $0.23(13)$ & $0.17(11)$ & $<0.01$ & $0.18(11)$ & $0.30(14)$ & $0.56(15)$ & $0.70(16)$ \\
\hline \multirow{3}{*}{$12,2009 / \mathrm{CEC}$} & UT & $0.12(3)$ & $0.65(8)$ & $0.72(17)$ & $1.34(8)$ & $1.06(12)$ & $0.68(1)$ & $1.40(7)$ \\
\hline & MT & $0.34(9)$ & $0.75(4)$ & $<0.01$ & $1.04(3)$ & $0.69(2)$ & $0.98(3)$ & $1.33(2)$ \\
\hline & LMT & $0.08(2)$ & $0.09(3)$ & $<0.01$ & $0.14(1)$ & $0.12(2)$ & $0.19(1)$ & $0.33(3)$ \\
\hline \multirow{3}{*}{$12,2009 / \mathrm{ECS}$} & UT & $0.23(8)$ & $0.63(8)$ & $0.80(40)$ & $1.35(23)$ & $1.19(30)$ & $0.66(4)$ & $1.47(27)$ \\
\hline & MT & $0.46(9)$ & $0.77(5)$ & $<0.01$ & $1.04(9)$ & $0.72(5)$ & $1.05(5)$ & $1.31(7)$ \\
\hline & LMT & $0.18(2)$ & $0.30(9)$ & $<0.01$ & $0.13(1)$ & $0.25(1)$ & $0.36(2)$ & $0.48(5)$ \\
\hline \multirow{3}{*}{ All profiles } & UT & $0.16(7)$ & $0.59(9)$ & $0.44(40)$ & $1.16(25)$ & $0.90(30)$ & $0.62(8)$ & $1.21(28)$ \\
\hline & MT & $0.50(15)$ & $0.83(11)$ & $<0.01$ & $1.03(8)$ & $0.73(9)$ & $1.00(9)$ & $1.23(13)$ \\
\hline & LMT & $0.20(12)$ & $0.21(15)$ & $<0.01$ & $0.20(14)$ & $0.26(15)$ & $0.46(25)$ & $0.59(26)$ \\
\hline
\end{tabular}

doubled the DFS value. The addition of the MW measurement was thus the most effective way of improving the retrieval of the ozone profile in the UT region.

In the MT region, the TIR measurement was the main contributor of DFS information. The DFS values were $0.50 \pm$ $0.16,0.83 \pm 0.11$, and less than 0.01 for the UV, TIR, and MW wavelength ranges, respectively. The DFS values increased in the same way as in the UT calculation by adding measurements in different wavelength ranges. The average DFS values for the 20 profiles were $1.03 \pm 0.09,0.73 \pm$ $0.09,1.00 \pm 0.09$ and $1.23 \pm 0.13$ for TIR $+\mathrm{MW}, \mathrm{UV}+\mathrm{MW}$, $\mathrm{UV}+\mathrm{TIR}$, and UV + TIR + MW, respectively. It should be noted that, although the MW measurement provided no information on ozone in the MT region because of atmospheric opacity, it nevertheless increased the DFS in the MT region from 1.00 to 1.23 (approximately $23 \%$ ) for the TIR + UV measurement. This indicates that information on ozone in the stratosphere and UT, where the sensitivity of the MW measurement is high, is also important for retrieval of the ozone profile for the MT region.

The DFS values in the LMT region were generally smaller than those in the UT and MT regions. They were calculated to be $0.20 \pm 0.13,0.21 \pm 0.15$, less than $0.01,0.20 \pm 0.14$, $0.26 \pm 0.15,0.46 \pm 0.25$, and $0.60 \pm 0.27$ for UV, TIR, MW, $\mathrm{TIR}+\mathrm{MW}, \mathrm{UV}+\mathrm{MW}, \mathrm{UV}+\mathrm{TIR}$, and UV + TIR + MW, respectively. The DFS values of the UV and TIR wavelength ranges were almost the same, while the MW measurements had no sensitivity in the LMT region. Similar to that in the MT region, the DFS value for the UV + TIR measurement (0.46) increased to 0.60 (about $30 \%$ ) as a result of adding the MW measurement. We note that the DFS value for the TIR measurement for ECS in December was larger than that for the TIR + MW measurement. The averaging kernel matrix in the LMT region for the TIR measurement in this case was discontinuously large. Since discontinuity generally occurs in the averaging kernel due to mathematical factors, not atmospheric physical factors, we do not discuss the DFS value for the TIR measurement in the ECS in December case.

We compared our results with those of previous studies of estimating the tropospheric ozone sensitivity using DFS. The DFS values for UV, TIR, and UV + TIR measurements are summarized in Table 5. Since the scenarios of the simulation or measurement are different between this work and the previous studies, the DFS values cannot be directly compared. We thus calculated the relative differences between the DFS values for the UV + TIR measurements and the mean of the DFS values for the UV and TIR measurements. The relative difference for our simulation for all profiles averaged was $126 \%$, which shows good agreement with those of Fu et al. (2013; 139\%), Cuesta et al. (2013; $104 \%)$, and Natraj et al. (2011; $115 \%)$.

The pressure of maximum sensitivity, PMS, for the ozone partial column should be located within the corresponding vertical region. The PMS values for the UT calculation for all cases were located within the corresponding range (215$383 \mathrm{hPa}$ ) when two or more wavelength ranges were combined. This was also observed for the MT calculation. For the LMT calculation, this was observed only when three wavelength ranges were combined. The PMS values for all profiles averaged for the LMT were 783 and $808 \mathrm{hPa}$ for the UV + TIR and UV + TIR + MW measurements, respectively. The PMS value was increased approximately $3 \%$ by 

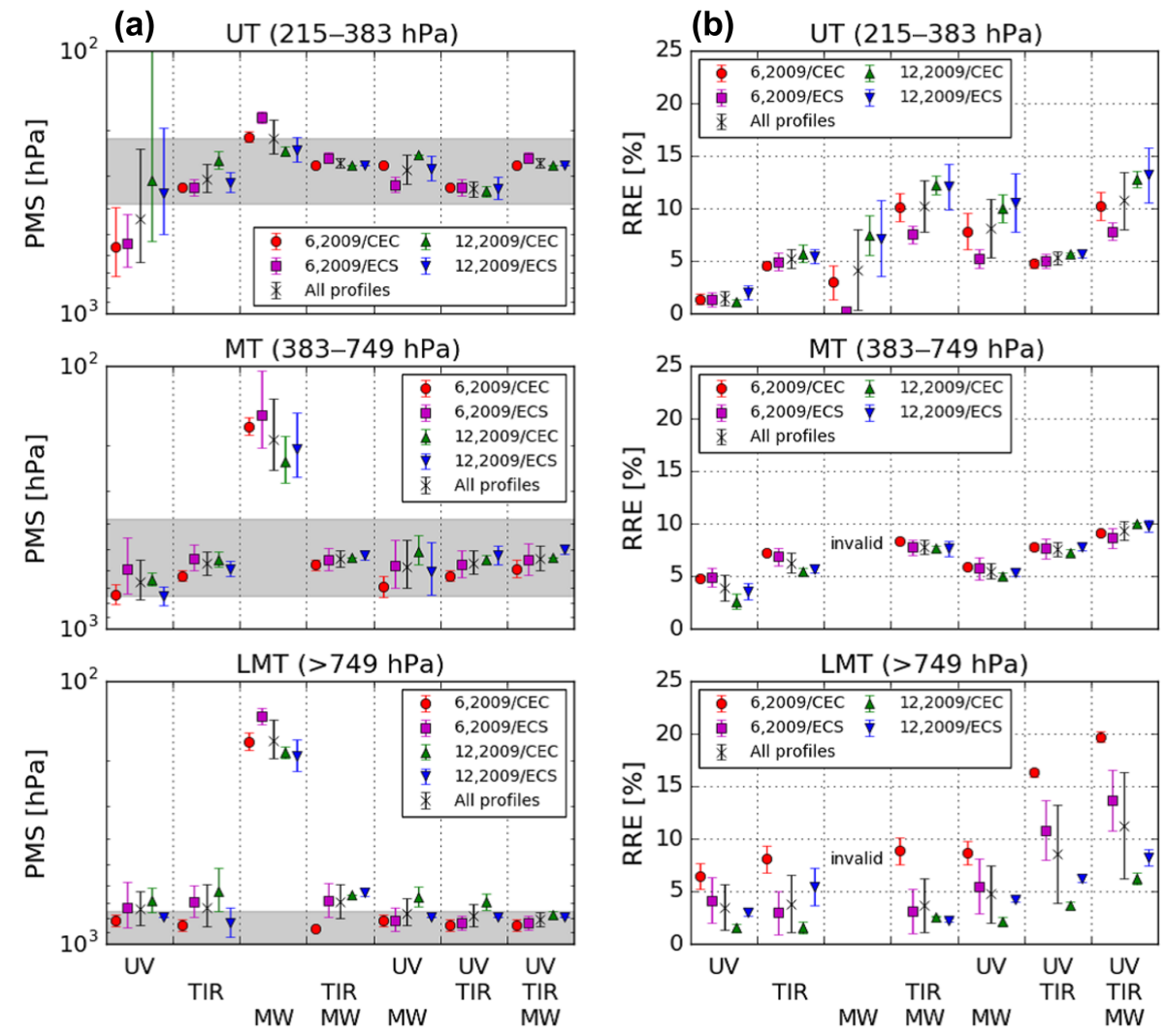

Figure 4. Same as Fig. 3 but for the PMS (a) and RRE (b). The gray shaded area represents the vertical region that corresponds to UT, MT, and LMT.

Table 5. Comparison of DFS in the LMT region with those of previous studies. Method and scenarios differed, so relative difference between DFS value for UV + TIR measurement (DFS $U$ +TIR) and mean of DFS values for UV and TIR measurements $\left(D_{F} S_{U V}, D_{\text {DFS }}\right.$ TIR) were used for comparison. The relative difference was calculated by $\left.\left(\mathrm{DFS}_{\mathrm{UV}}+\mathrm{TIR}-\mathrm{Mean}\left(\mathrm{DFS}_{\mathrm{UV}}, \mathrm{DFS}_{\mathrm{TIR}}\right)\right) / \mathrm{Mean}_{(\mathrm{DFS}} \mathrm{UV}_{\mathrm{V}}, \mathrm{DFS}_{\mathrm{TIR}}\right)$.

\begin{tabular}{lrrrrrl}
\hline & DFS $_{\text {UV }}$ & DFS $_{\text {TIR }}$ & Mean DFS $_{\text {UV }}$, DFS $\left._{\text {TIR }}\right)$ & DFS $_{\text {UV+TIR }}$ & Rel. dif. & Definition of LMT \\
\hline This work & 0.20 & 0.21 & 0.203 & 0.458 & $126 \%$ & $>749 \mathrm{hPa}$ \\
Fu et al. (2013) & 0.10 & 0.21 & 0.15 & 0.37 & $139 \%$ & $>700 \mathrm{hPa}$ \\
Cuesta et al. (2013) & 0.08 & 0.20 & 0.14 & 0.285 & $104 \%$ & $<3 \mathrm{~km}$ \\
Natraj et al. (2011) & 0.26 & 0.27 & 0.265 & 0.57 & $115 \%$ & $>800 \mathrm{hPa}$ \\
\hline
\end{tabular}

* DFS values over land and ocean are averaged.

adding the MW measurement to the combined UV + TIR measurement, although the PMS value in the MW measurement for the LMT was lower than $300 \mathrm{hPa}$.

The reduction rate of error, RRE, for the partial column of ozone calculated using Eq. (14) is shown on the right in Fig. 4. The RRE was approximately $0-20 \%$ in the UT, MT, and LMT regions. It was generally higher when more wavelength ranges were combined in the ozone synergetic retrieval, as shown by the DFS values plotted in Fig. 3. The RRE value for all profiles averaged was $36 \%$ for the LMT calculation and $39 \%$ for the UV + TIR and $\mathrm{UV}+\mathrm{TIR}+\mathrm{MW}$ measurements. Adding the MW measurement increased the RRE by $3 \%$. The DFS, PMS, and RRE values all show a certain increase in the retrieval sensitivity of the LMT ozone profile.

The sensitivity of MW measurement in the UT region largely depended on the atmospheric profile used, and this dependency was reflected in the wavelength combinations including the MW measurement. As shown in Fig. 3, the DFS values in the MW measurement for the UT in December for both areas were larger than those for June. The sensitivity of the MW measurements in the UT region increased for profiles with large amounts of the UT ozone. In the LMT, the DFS values of the UV and TIR measurements depended greatly on the atmospheric profiles. The average value of the partial column of ozone in the LMT region for CEC in June 
(a)

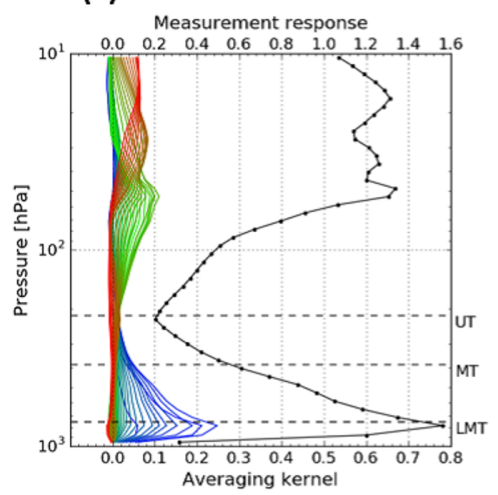

(d) (b)

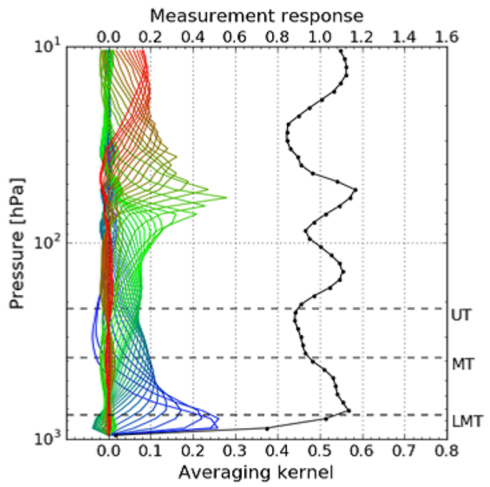

(e)

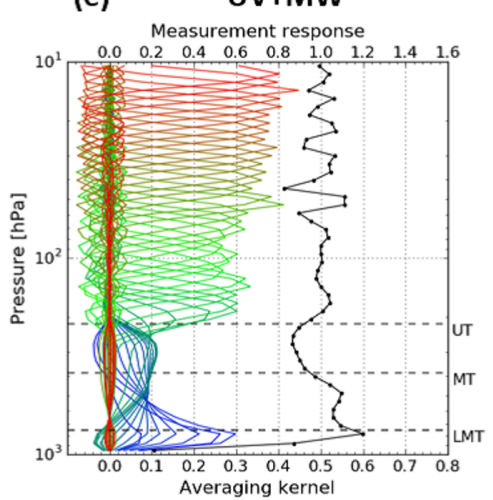

(c) $\quad \mathrm{MW}$

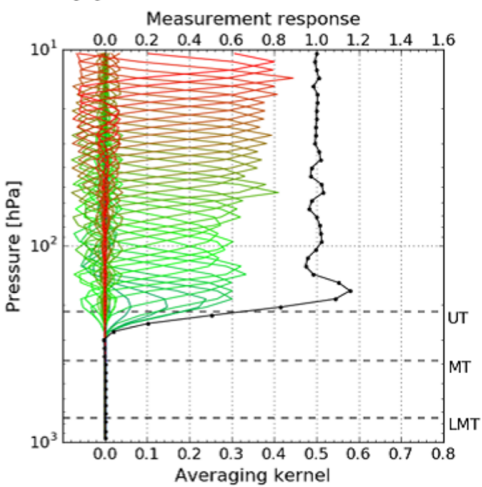

(f)

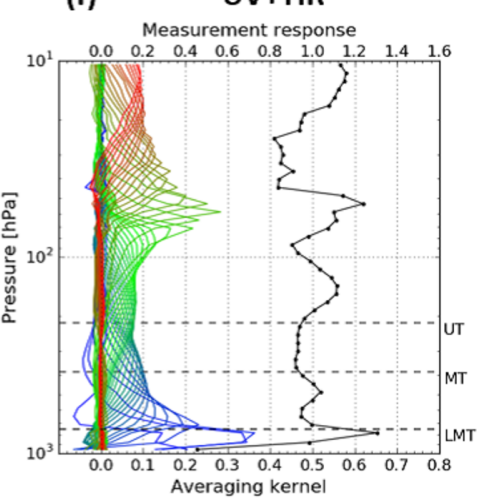

(g)

$\mathrm{UV}+\mathrm{TIR}+\mathrm{MW}$

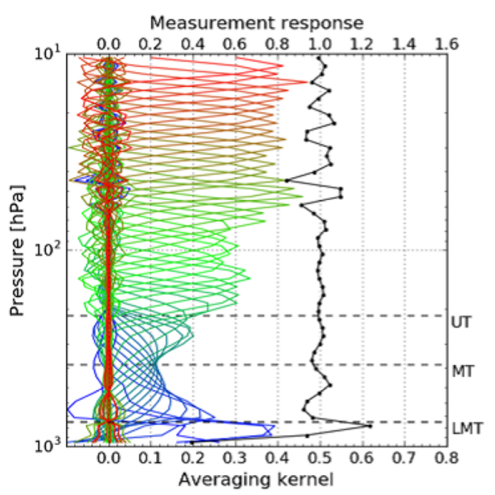

Figure 5. Averaging kernels for atmospheric profile no. 01 (more ozone enhancement in LMT, CEC in June 2009) for seven wavelength measurements: (a) UV, (b) TIR, (c) MW, (d) UV + TIR, (e) UV + MW, (f) TIR + MW, and (g) UV + TIR + MW. Measurement responses are shown by black dots and lines.

was $5.03 \times 10^{21} \mathrm{~m}^{-2}$, the largest among the four cases. Only the DFS value in the UV + TIR + MW for CEC in June was larger than unity $(1.03 \pm 0.01)$.

More details of the vertical characteristics are discussed using the averaging kernel matrix A. Figures 5 and 6 show A and $\boldsymbol{m}$ obtained from the simulations using atmospheric profiles nos. 01 and 02 for all wavelength combinations. The DFS values in the LMT for the UV + TIR + MW measurements of profiles nos. 01 and 02 were respectively estimated to be 1.04 and 0.27 , which were the highest and lowest values among the 20 profiles. For profile no. 01, the UV, TIR, and MW measurements provided information on the LMT, the MT-to-UT layer, and the UT-to-stratosphere layer, respectively. The UV and TIR measurements were important to retrieve the ozone amount in the LMT when only one wavelength range was used because their peaks in the row of $\mathbf{A}$ were located in the LMT region. The FWHM of the row of $\mathbf{A}$ for the UV and TIR measurements in the LMT was approxi- 
(a)

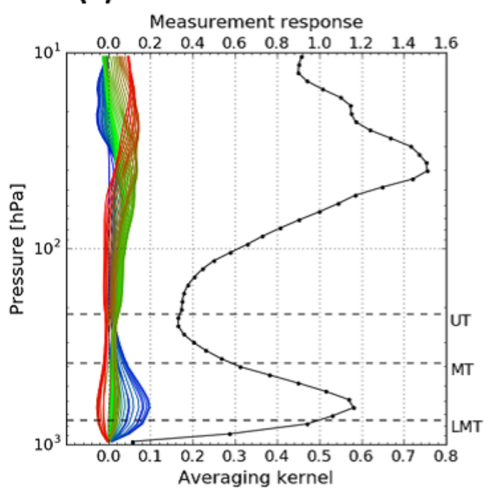

(d)

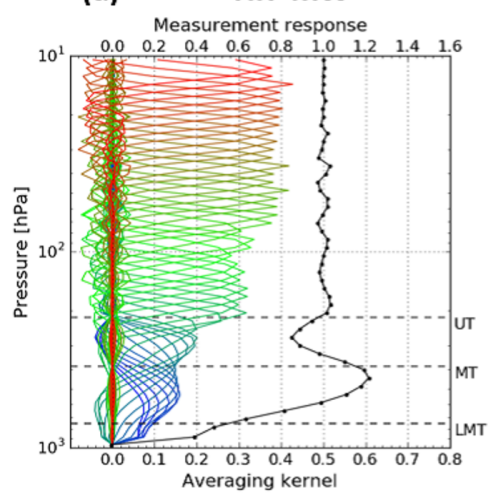

(g) UV+TIR+MW

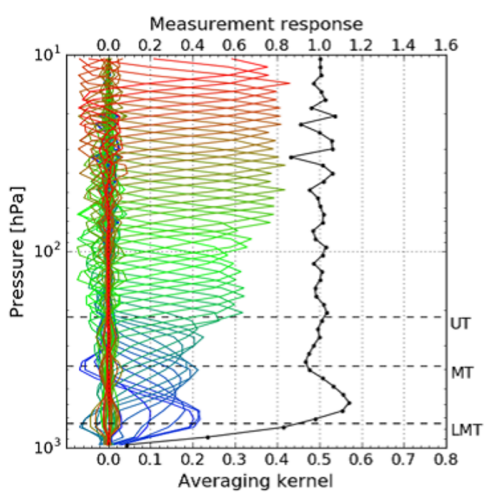

(b)

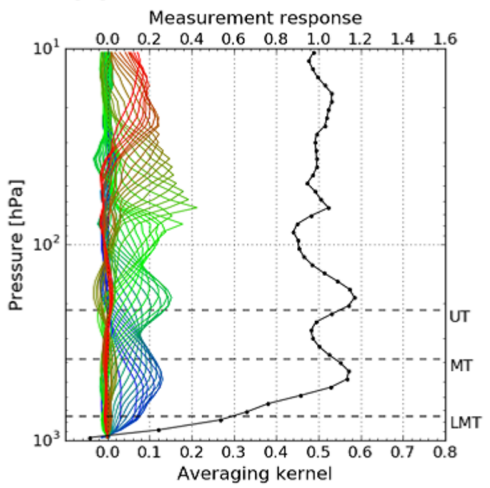

(e)

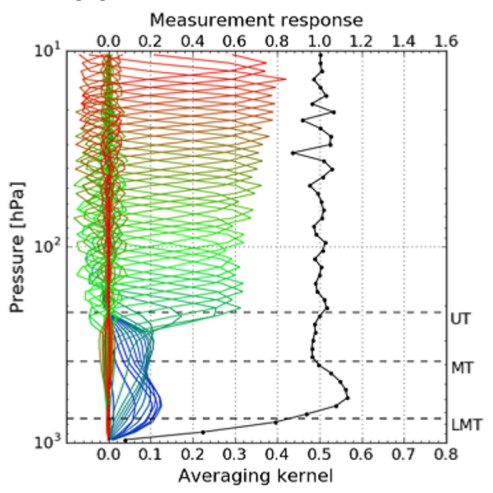

MW

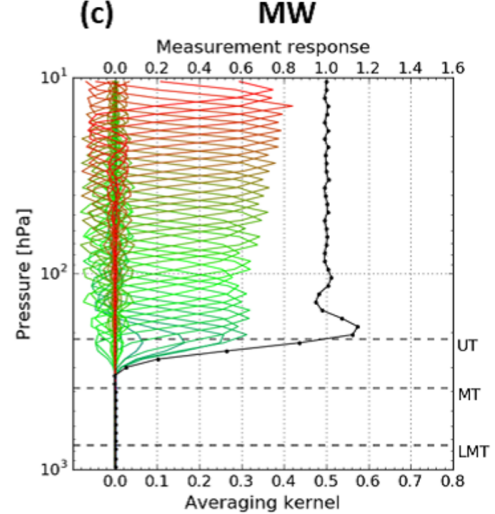

(f)

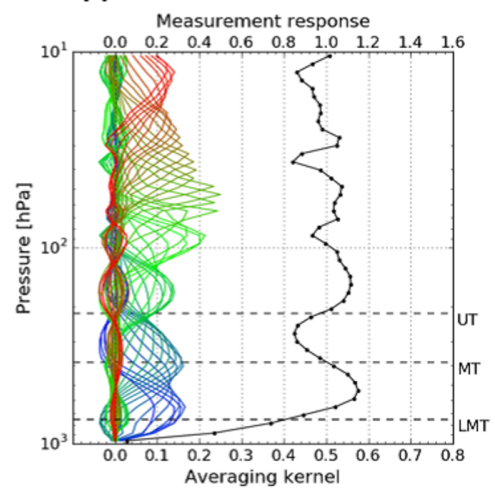

Figure 6. Same as Fig. 5 but for profile no. 12 (less ozone in LMT, CEC in December 2009).

mately $3 \mathrm{~km}$. The peak value in the row of $\mathbf{A}$ increased from 0.25 for the UV and TIR measurements to 0.35 when the two measurements were combined. Combining these measurements improves the sensitivity of retrieval of the LMT ozone amount, as shown in previous studies (Landgraf and Hasekamp, 2007; Worden et al., 2007; Natraj et al., 2011; Cuesta et al., 2013; Fu et al., 2013). Adding the MW measurement further increased it to 0.4 . For profile no. 12 (less ozone in the LMT), the peak of the row of $\mathbf{A}$ for the UV measurement was located in the MT (maximum value of 0.1 ). Although the peak value in the MT increased to 0.23 as a re- sult of combining the TIR and MW measurements, the peak value in the LMT remained low.

Additionally, we performed a sensitivity study for the DFS, PMS, and RRE using several $\sigma_{\mathrm{a}}$ values in order to obtain error volume. Figure 7 shows the DFS, PMS, and RRE values with $\sigma_{\mathrm{a}}$ of $100,50,30,20$, and $10 \%$. Here the calculation results for all 20 profiles were averaged. The DFS values decreased as the $\sigma_{\text {a }}$ value decreased for all wavelength combinations considered in this study. This behavior was also observed for the RRE results. The PMS value seemed to be located in the corresponding vertical region when the $\sigma_{\mathrm{a}}$ value 

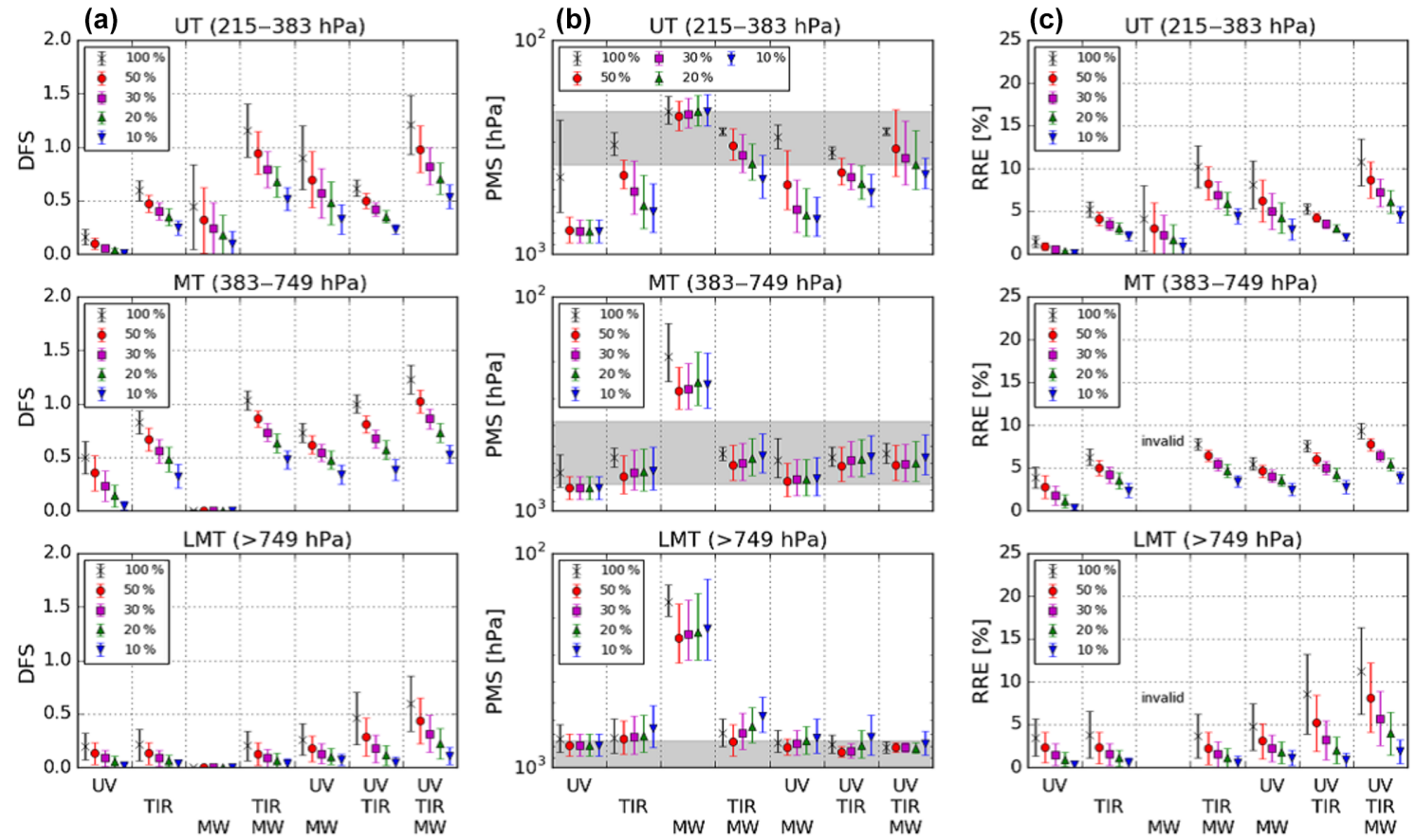

Figure 7. Values of DFS (a), PMS (b), and RRE (c) for upper troposphere (UT, 215-383 hPa), middle troposphere (MT, 383-749 hPa), and lowermost troposphere (LMT, $>749 \mathrm{hPa}$ ) for 20 profiles averaged: $\sigma_{\mathrm{a}}$ values of $100 \%$ (black), $50 \%$ (red), $30 \%$ (purple), $20 \%$ (green), and $10 \%$ (blue) of the log-based a priori VMR.

increased. The behavior of the relative differences of DFS, PMS, and RRE for the different wavelength combination was the same for all $\sigma_{\mathrm{a}}$ cases. An increase in retrieval sensitivity of the LMT ozone amount by adding the MW measurement was observed for all $\sigma_{\mathrm{a}}$ cases considered in this sensitivity study.

Our results show that introducing MW limb measurement increases the sensitivity of tropospheric ozone profile retrieval. However, several factors may cause bias and uncertainty in the retrieval results and thus should be considered before the proposed retrieval method is implemented. Discrepancy among spectroscopic parameters for several wavelength ranges is a major source of errors. For ozone profile retrieval using MW limb measurement, the spectroscopic parameters are the major error source. It was reported that an error of approximately $3-5 \%$ was caused by uncertainties in the air-broadening coefficient and line intensity in the case of the SMILES observation (Kasai et al., 2013), which is comparable to the approximately $4 \%$ uncertainty in the spectroscopic parameters in the UV and TIR wavelength ranges (Gratien et al., 2010). The tangent height correction can also be a large error source for the MW limb measurement (Kasai et al., 2013). The tangent height is a key parameter for determining the field of view, so uncertainty in the tangent height causes a discrepancy between the atmospheric layer assumed in the simulation and the true atmospheric layer. This discrepancy critically affects the retrieval of the ozone profile in both the stratosphere and the troposphere, and may cause bias in the correction of the time delay between MW limb measurement and other nadir measurements. In this study, we assumed that a time difference of approximately $5 \mathrm{~min}$ between the UV and TIR nadir down-looking and the MW limb sounding could be ignored. If the time difference is actually long enough to need correction, three-dimensional atmospheric modeling including the field of view of the MW limb measurement should be performed.

As a whole, it was shown that retrieval of the tropospheric ozone profile was improved by adding MW limb measurements to UV and TIR nadir measurements. In the LMT region, the DFS value was estimated to be increased by approximately $30 \%$. The DFS values were estimated to be 0.75 and 0.66 over land and ocean, respectively, for the upcoming IASI-NG and UVNS missions (Constantino et al., 2017). If MW limb measurement is implemented into the synergetic retrieval, the DFS value is estimated to increase to 0.98 and 0.86 over land and ocean, respectively. Our feasibility study has shown that it is possible to retrieve the ozone profile in the LMT with a DFS value of unity.

\section{Conclusions}

We performed a feasibility study of obtaining vertically resolved ozone profiles in the troposphere with synergetic retrieval using various combinations of three wavelength ranges (UV, TIR, and MW). The observation geometries used 
in this study were the nadirs for the UV and TIR measurements and limb for the MW measurement from low-Earth orbit $(300 \mathrm{~km}$, the height of the ISS). The urban (CEC) and ocean (ECS) areas in June and December 2009 were assumed for this study. We evaluated the sensitivities of tropospheric ozone profile retrieval for the three vertical regions (UT, 215$383 \mathrm{hPa}$; MT, 383-749 $\mathrm{hPa}$; and LMT, > $749 \mathrm{hPa}$ ) in terms of the degree of freedom for signal (DFS) based on the OEM calculation. The pressure of maximum sensitivity (PMS) and the reduction rate of error (RRE) for the partial column were also used as an indicator of the sensitivity evaluation.

The TIR measurement was most sensitive for retrieving the ozone profile in the UT when only one wavelength range was used. The addition of MW measurement was most effective at improving sensitivity in the UT when combining several wavelength ranges. The DFS values in the UT for all 20 profiles averaged were $0.62 \pm 0.08$ and $1.21 \pm 0.28$ for the UV + TIR and UV + TIR + MW measurements, respectively. In the MT region, the contribution of the TIR measurement was dominant in the DFS calculation. The average DFS value of the TIR measurement for all profiles averaged was $0.83 \pm 0.11$. It was increased to more than unity by adding either the UV or MW measurement. The UV and TIR measurements were dominant in the retrieval of the ozone profile in the LMT region. The DFS value in the LMT greatly depended on the ozone abundance. It was larger for a larger partial column of the LMT ozone. The largest DFS value in the LMT for UV + TIR + MW measurement $(1.03 \pm 0.01)$ was obtained for CEC in June which is the case with the largest LMT ozone enhancement with the partial column in the LMT ozone (approximately $5 \times 10^{21} \mathrm{~m}^{-2}$ ).

The MW limb measurement alone provided less information in the MT and LMT regions. The DFS values were less than 0.01 and the PMS was located in a vertical region higher than the MT and LMT. Nevertheless, adding MW measurement to the combined UV and TIR measurement improved sensitivity not only in the UT but also in the MT and LMT. The DFS values were increased by 96,23 , and $30 \%$ in the UT, MT, and LMT, respectively, by adding the MW measurement to the UV + TIR measurement. This indicates that reducing uncertainty about ozone abundance in the stratosphere may be important for accurately estimating the tropospheric ozone profile.

Data availability. In this study, the atmospheric profiles are synthesized using the AQF system, the MERRA data and the CIRA data. Contact Katsuyuki Noguchi and Hitoshi Irie for the atmospheric profiles used here. The MERRA data are available on the NASA GES DISC database (https://goldsmr3.gesdisc.eosdis.nasa. gov/data/MERRA/MAI6NVANA.5.2.0/, NASA, 2018).

Competing interests. The authors declare that they have no conflict of interest.
Acknowledgements. This work was supported by the Funding Program for Next Generation World-Leading Researchers (NEXT Program; no. GR101). This research was partly supported by Coordination Funds for Promoting Space Utilization by the Ministry of Education, Culture, Sports, Science and Technology (MEXT), Japan. We are grateful to Masayuki Takigawa for providing us with his numerical simulation data for this study. The MERRA data used in this study were provided by the Global Modeling and Assimilation Office (GMAO) at NASA Goddard Space Flight Center through the NASA GES DISC online archive. We made use of CIRA-86. We thank Kenichi Kikuchi for discussing the specifications of the MW instrument proposed for the Air Pollution Observations from the ISS with us. We thank our colleagues of the Aura MLS team (JPL) for a valuable discussion on the frequency selection of the APOLLO MW instrument. We are grateful to Alexei Rozanov for giving many useful comments on SCIATRAN.

Edited by: Michel Van Roozendael

Reviewed by: two anonymous referees

\section{References}

Bak, J., Kim, J. H., Spurr, R. J. D., Liu, X., and Newchurch, M. J.: Sensitivity study of ozone retrieval from UV measurements on geostationary platforms, Remote Sens. Environ., 118, 309-319, 2012.

Baldridge, A. M., Hook, S. J., Grove, C. I., and Rivera, G.: The ASTER spectral library version 2.0, Remote Sens. Environ., 113, 711-715, 2009.

Baron, P., Mendrok, J., Kasai, Y., Ochiai, S., Seta, T., Sagi, K., Suzuki, K., Sagawa, H., and Urban, J.: AMATERAU: Model for atmospheric terahertz radiation analysis and simulation, Journal of National Institute of Information and Communications Technology, 55, 109-121, 2008.

Baron, P., Urban, J., Sagawa, H., Möller, J., Murtagh, D. P., Mendrok, J., Dupuy, E., Sato, T. O., Ochiai, S., Suzuki, K., Manabe, T., Nishibori, T., Kikuchi, K., Sato, R., Takayanagi, M., Murayama, Y., Shiotani, M., and Kasai, Y.: The Level 2 research product algorithms for the Superconducting Submillimeter-Wave Limb-Emission Sounder (SMILES), Atmos. Meas. Tech., 4, 2105-2124, https://doi.org/10.5194/amt-4-2105-2011, 2011.

Brinksma, E. J., Bracher, A., Lolkema, D. E., Segers, A. J., Boyd, I. S., Bramstedt, K., Claude, H., Godin-Beekmann, S., Hansen, G., Kopp, G., Leblanc, T., McDermid, I. S., Meijer, Y. J., Nakane, H., Parrish, A., von Savigny, C., Stebel, K., Swart, D. P. J., Taha, G., and Piters, A. J. M.: Geophysical validation of SCIAMACHY Limb Ozone Profiles, Atmos. Chem. Phys., 6, 197209, https://doi.org/10.5194/acp-6-197-2006, 2006.

Clerbaux, C., Boynard, A., Clarisse, L., George, M., Hadji-Lazaro, J., Herbin, H., Hurtmans, D., Pommier, M., Razavi, A., Turquety, S., Wespes, C., and Coheur, P.-F.: Monitoring of atmospheric composition using the thermal infrared IASI/MetOp sounder, Atmos. Chem. Phys., 9, 6041-6054, https://doi.org/10.5194/acp-96041-2009, 2009.

Clough, S. A., Shephard, M. W., Mlawer, E. J., Delamere, J. S., Iacono, M. J., Cady-Pereira, K., Boukabara, S., and Brown, P. D.: Atmospheric radiative transfer modeling: a summary of the AER codes, J. Quant. Spectrosc. Ra., 91, 233-244, 2005. 
Clough, S. A., Shephard, M. W., Worden, J., Brown, P. D., Worden, H. M., Luo, M., Rodgers, C. D., Rinsland, C. P., Goldman, A., Brown, L., Kulawik, S. S., Eldering, A., Lampel, M., Osterman, G., Beer, R., Bowman, K., Cady-Pereira, K. E., and Mlawer, E. J.: Forward model and Jacobians for tropospheric emission spectrometer retrievals, IEEE T. Geosci. Remote, 44, 1308-1323, 2006.

Costantino, L., Cuesta, J., Emili, E., Coman, A., Foret, G., Dufour, G., Eremenko, M., Chailleux, Y., Beekmann, M., and Flaud, J.-M.: Potential of multispectral synergism for observing ozone pollution by combining IASI-NG and UVNS measurements from the EPS-SG satellite, Atmos. Meas. Tech., 10, 1281-1298, https://doi.org/10.5194/amt-10-1281-2017, 2017.

Cuesta, J., Eremenko, M., Liu, X., Dufour, G., Cai, Z., Höpfner, M., von Clarmann, T., Sellitto, P., Foret, G., Gaubert, B., Beekmann, M., Orphal, J., Chance, K., Spurr, R., and Flaud, J.-M.: Satellite observation of lowermost tropospheric ozone by multispectral synergism of IASI thermal infrared and GOME-2 ultraviolet measurements over Europe, Atmos. Chem. Phys., 13, 9675-9693, https://doi.org/10.5194/acp-13-9675-2013, 2013.

Dentener, F., Keating, T., and Akimoto, H.: HTAP, UNECE: Hemispheric Transport of Air Pollution 2010: Part A: Ozone and Particulate Matter, Air Pollution Studies No. 17, edited by: Dentener, F., Keating, T., and Akimoto, H., ECE/EN.Air/100, ISSN 1014-4625, ISBN 978-92-1-117043-6, 2010.

Fleming, E. L., Chandra, S., Schoeberl, M. R., and Barnett, J. J.: Monthly mean global climatology of temperature, wind, geopotential height and pressure for $0-120 \mathrm{~km}$, NASA Techn. Memo. 100697, Natl. Aeronaut. and Space Admin., Washington, D.C., 1988.

Fleming, E. L., Chandra, S., Barnett, J. J., and Corney, M.: Zonal mean temperature, pressure, zonal wind and geopotential height as functions of latitude, Adv. Space Res., 10, 11-59, 1990.

Fu, D., Worden, J. R., Liu, X., Kulawik, S. S., Bowman, K. W., and Natraj, V.: Characterization of ozone profiles derived from Aura TES and OMI radiances, Atmos. Chem. Phys., 13, 3445-3462, https://doi.org/10.5194/acp-13-3445-2013, 2013.

Fujinawa, T., Kasai, Y., and Mahani, M.: uvSCOPE team, and APOLLO mission team: Japanese future mission for air quality uvSCOPE and APOLLO, 8th Atmospheric Limb workshop Abstracts, https://www.chalmers.se/en/conference/ limb-workshop-2015/Documents/Abstracts_Limb_Workshop_ 2015.pdf (last access: 14 March 2018), 2015.

Gratien, A., Picquet-Varrault, B., Orphal, J., Doussin, J. F., and Flaud, J. M.: New laboratory intercomparison of the ozone absorption coefficients in the mid-infrared $(10 \mu \mathrm{m})$ and ultraviolet (300-350 nm) spectral regions, J. Phys. Chem. A, 114, 1004510048, https://doi.org/10.1021/jp103992f, 2010.

Grell, G. A., Peckham, S. E., Schmitz, R., McKeen, S. A., Frost, G., Skamarock, W. C., and Eder, B.: Fully coupled "online" chemistry within the WRF model, Atmos. Environ., 39, 6957-6975, 2005.

Hayashida, S., Liu, X., Ono, A., Yang, K., and Chance, K.: Observation of ozone enhancement in the lower troposphere over East Asia from a space-borne ultraviolet spectrometer, Atmos. Chem. Phys., 15, 9865-9881, https://doi.org/10.5194/acp-159865-2015, 2015.
Hess, M., Koepke, P., and Schult, I.: Optical properties of aerosols and clouds: The software package OPAC, B. Am. Meteorol. Soc., 79, 831-844, 1998.

Kasai, Y., Kita, K., Kanaya, Y., Gmap-Asia, and Apollo Mission Team: The Japanese Air Pollusion Observation Missions, GMAP-Asia and APOLLO, AGU Fall Meeting Abstracts, San Francisco, Calif., 5-9 December 2011.

Kasai, Y., Sagawa, H., Kuroda, T., Manabe, T., Ochiai, S., Kikuchi, K., Nishibori, T., Baron, P., Mendrok, J., Hartogh, P., Murtagh, D., Urban, J., von Schéele, F., and Frisk, U.: Overview of the Martian atmospheric submillimetre sounder FIRE, Planet. Space Sci., 63, 62-82, 2012.

Kasai, Y., Sagawa, H., Kreyling, D., Dupuy, E., Baron, P., Mendrok, J., Suzuki, K., Sato, T. O., Nishibori, T., Mizobuchi, S., Kikuchi, K., Manabe, T., Ozeki, H., Sugita, T., Fujiwara, M., Irimajiri, Y., Walker, K. A., Bernath, P. F., Boone, C., Stiller, G., von Clarmann, T., Orphal, J., Urban, J., Murtagh, D., Llewellyn, E. J., Degenstein, D., Bourassa, A. E., Lloyd, N. D., Froidevaux, L., Birk, M., Wagner, G., Schreier, F., Xu, J., Vogt, P., Trautmann, T., and Yasui, M.: Validation of stratospheric and mesospheric ozone observed by SMILES from International Space Station, Atmos. Meas. Tech., 6, 2311-2338, https://doi.org/10.5194/amt6-2311-2013, 2013.

Kikuchi, K., Nishibori, T., Ochiai, S., Ozeki, H., Irimajiri, Y., Kasai, Y., Koike, M., Manabe, T., Mizukoshi, K., Murayama, Y., Nagahama, T., Sano, T., Sato, R., Seta, M., Takahashi, C., Takayanagi, M., Masuko, H., Inatani, J., Suzuki, M., and Shiotani, M.: Overview and early results of the Superconducting Submillimeter-Wave Limb-Emission Sounder (SMILES), J. Geophys. Res.-Atmos., 115, D23306, https://doi.org/10.1029/2010JD014379, 2010.

Kleipool, Q. L., Dobber, M. R., de Haan, J. F., and Levelt, P. F.: Earth surface reflectance climatology from 3 years of OMI data, J. Geophys. Res.-Atmos., 113, D18308, https://doi.org/10.1029/2008JD010290, 2008.

Kyrölä, E., Tamminen, J., Leppelmeier, G. W., Sofieva, V., Hassinen, S., Bertaux, J. L., Hauchecorne, A., Dalaudier, F., Cot, C., Korablev, O., Fanton d'Andon, O., Barrot, G., Mangin, A., Théodore, B., Guirlet, M., Etanchaud, F., Snoeij, P., Koopman, R., Saavedra, L., Fraisse, R., Fussen, D., and Vanhellemont, F.: GOMOS on Envisat: an overview, Adv. Space Res., 33, 1020-1028, 2004.

Landgraf, J., and Hasekamp, O. P.: Retrieval of tropospheric ozone: The synergistic use of thermal infrared emission and ultraviolet reflectivity measurements from space, J. Geophys. Res.-Atmos., 112, D08310, https://doi.org/10.1029/2006JD008097, 2007.

Levelt, P. F., van den Oord, G. H. J., Dobber, M. R., Malkki, A., Visser, H., de Vries, J., Stammes, P., Lundell, J. O. V., and Saari, H.: The ozone monitoring instrument, IEEE T. Geosci. Remote, 44, 1093-1101, 2006.

Munro, R., Eisinger, M., Anderson, C., Callies, J., Corpaccioli, E., Lang, R., Lefebvre, A., Livschitz, Y., and Albinana, A. P.: GOME-2 on MetOp, in: Proc. of The 2006 EUMETSAT Meteorological Satellite Conference, Helsinki, Finland, 12-16, 2006.

National Aeronautics and Space Administration (NASA): GES DISC Data Archive, available at: https://goldsmr3.gesdisc. eosdis.nasa.gov/data/MERRA/MAI6NVANA.5.2.0/, last access: 20 March 2018. 
Natraj, V., Liu, X., Kulawik, S., Chance, K., Chatfield, R., Edwards, D. P., Eldering, A., Francis, G., Kurosu, T., Pickering, K., Spurr, R., and Worden, H.: Multi-spectral sensitivity studies for the retrieval of tropospheric and lowermost tropospheric ozone from simulated clear-sky GEO-CAPE measurements, Atmos. Environ., 45, 7151-7165, 2011.

Noguchi, K., Richter, A., Rozanov, V., Rozanov, A., Burrows, J. P., Irie, H., and Kita, K.: Effect of surface BRDF of various land cover types on geostationary observations of tropospheric $\mathrm{NO}_{2}$, Atmos. Meas. Tech., 7, 3497-3508, https://doi.org/10.5194/amt7-3497-2014, 2014.

Osterman, G. B., Kulawik, S. S., Worden, H. M., Richards, N. A. D., Fisher, B. M., Eldering, A., Shephard, M. W., Froidevaux, L., Labow, G., Luo, M., Herman, R. L., Bowman, K. W., and Thompson, A. M.: Validation of Tropospheric Emission Spectrometer (TES) measurements of the total, stratospheric, and tropospheric column abundance of ozone, J. Geophys. Res.-Atmos., 113, D15S16, https://doi.org/10.1029/2007JD008801, 2008.

Pardo, J. R., Serabyn, E., and Cernicharo, J.: Submillimeter atmospheric transmission measurements on Mauna Kea during extremely dry El Niño conditions: Implications for broadband opacity contributions, J. Quant. Spectrosc. Ra., 68, 419-433, 2001.

Pickett, H. M., Poynter, R. L., Cohen, E. A., Delitsky, M. L., Pearson, J. C., and Müller, H. S. P.: Submillimeter, millimeter and microwave spectral line catalog, J. Quant. Spectrosc. Ra., 60, 883890, https://doi.org/10.1016/S0022-4073(98)00091-0, 1998.

Rienecker, M. M., Suarez, M. J., Gelaro, R., Todling, R., Bacmeister, J., Liu, E., Bosilovich, M. G., Schubert, S. D., Takacs, L., Kim, G. K., Bloom, S., Chen, J., Collins, D., Conaty, A., da Silva, A., Gu, W., Joiner, J., Koster, R. D., Lucchesi, R., Molod, A., Owens, T., Pawson, S., Pegion, P., Redder, C. R., Reichle, R., Robertson, F. R., Ruddick, A. G., Sienkiewicz, M., and Woollen, J.: MERRA: NASA's modern-era retrospective analysis for research and applications, J. Climate, 24, 3624-3648, 2011.

Rodgers, C. D.: Inverse methods for atmospheric sounding: theory and practice, Series on Atmospheric, Oceanic and Planetary Physics, World Scientific, 2, 3605-3609, 2000.

Rothman, L. S., Gordon, I. E., Barbe, A., Benner, D. C., Bernath, P. F., Birk, M., Boudon, V., Brown, L. R., Campargue, A., Champion, J. P., Chance, K., Coudert, L. H., Dana, V., Devi, V. M., Fally, S., Flaud, J. M., Gamache, R. R., Goldman, A., Jacquemart, D., Kleiner, I., Lacome, N., Lafferty, W. J., Mandin, J. Y., Massie, S. T., Mikhailenko, S. N., Miller, C. E., Moazzen-Ahmadi, N., Naumenko, O. V., Nikitin, A. V., Orphal, J., Perevalov, V. I., Perrin, A., Predoi-Cross, A., Rinsland, C. P., Rotger, M., Šimečková, M., Smith, M. A. H., Sung, K., Tashkun, S. A., Tennyson, J., Toth, R. A., Vandaele, A. C., and Vander Auwera, J.: The HITRAN 2008 molecular spectroscopic database, J. Quant. Spectrosc. Ra., 110, 533572, https://doi.org/10.1016/j.jqsrt.2009.02.013, 2009.

Rozanov, A., Rozanov, V., Buchwitz, M., Kokhanovsky, A., and Burrows, J. P.: SCIATRAN 2.0 - a new radiative transfer model for geophysical applications in the $175-2400 \mathrm{~nm}$ spectral region, Adv. Space Res., 36, 1015-1019, 2005.

Saitoh, N., Imasu, R., Ota, Y., and Niwa, Y.: $\mathrm{CO}_{2}$ retrieval algorithm for the thermal infrared spectra of the Greenhouse Gases Observing Satellite: Potential of retrieving $\mathrm{CO}_{2}$ vertical profile from high-resolution FTS sensor, J. Geophys. Res.-Atmos., 114, D17305, https://doi.org/10.1029/2008JD011500, 2009.

Sellitto, P., Del Frate, F., Solimini, D., and Casadio, S.: Tropospheric ozone column retrieval from ESA-Envisat SCIAMACHY nadir UV/VIS radiance measurements by means of a neural network algorithm, IEEE T. Geosci. Remote, 50, 9981011, https://doi.org/10.1109/TGRS.2011.2163198, 2012a.

Sellitto, P., Di Noia, A., Del Frate, F., Burini, A., Casadio, S., and Solimini, D.: On the role of visible radiation in ozone profile retrieval from nadir UV/VIS satellite measurements: An experiment with neural network algorithms inverting SCIAMACHY data, J. Quant. Spectrosc. Ra., 113, 1429-1436, https://doi.org/10.1016/j.jqsrt.2012.04.007, 2012b.

Sudo, K., Takahashi, M., Kurokawa, J., and Akimoto, H.: CHASER: A global chemical model of the troposphere: 1. Model description, J. Geophys. Res.-Atmos., 107, 4339, https://doi.org/10.1029/2001JD001113, 2002.

Takigawa, M., Niwano, M., Akimoto, H., and Takahashi, M.: Development of a one-way nested global-regional air quality forecasting model, SOLA, 3, 81-84, 2007.

Takigawa, M., Niwano, M., Akimoto, H., Takahashi, M., and Kobayashi, K.: Projection of surface ozone over East Asia in 2020, J. Agric. Meteorol., 65, 161-166, 2009.

Urban, J., Lautié, N., Le Flochmoën, E., Jiménez, C., Eriksson, P., de La Noë, J., Dupuy, E., Ekström, M., El Amraoui, L., Frisk, U., Murtagh, D., Olberg, M., and Ricaud, P.: Odin/SMR limb observations of stratospheric trace gases: Level 2 processing of $\mathrm{ClO}$, $\mathrm{N}_{2} \mathrm{O}, \mathrm{HNO}_{3}$, and $\mathrm{O}_{3}$, J. Geophys. Res.-Atmos., 110, D14307, https://doi.org/10.1029/2004JD005741, 2005.

Waters, J. W., Froidevaux, L., Harwood, R. S., Jarnot, R. F., Pickett, H. M., Read, W. G., Siegel, P. H., Cofield, R. E., Filipiak, M. J., Flower, D. A., Holden, J. R., Lau, G. K., Livesey, N. J., Manney, G. L., Pumphrey, H. C., Santee, M. L., Wu, D. L., Cuddy, D. T., Lay, R. R., Loo, M. S., Perun, V. S., Schwartz, M. J., Stek, P. C., Thurstans, R. P., Boyles, M. A., Chandra, K. M., Chavez, M. C., Chen, G. S., Chudasama, B. V., Dodge, R., Fuller, R. A., Girard, M. A., Jiang, J. H., Jiang, Y., Knosp, B. W., LaBelle, R. C., Lam, J. C., Lee, K. A., Miller, D., Oswald, J. E., Patel, N. C., Pukala, D. M., Quintero, O., Scaff, D. M., Snyder, W. V., Tope, M. C., Wagner, P. A., and Walch, M. J.: The earth observing system microwave limb sounder (EOS MLS) on the Aura satellite, IEEE T. Geosci. Remote, 44, 1075-1092, 2006.

WHO: Burden of Disease from Ambient Air Pollution for 2012, World Health Organization, Geneva, 2014.

Worden, J., Liu, X., Bowman, K., Chance, K., Beer, R., Eldering, A., Gunson, M., and Worden, H.: Improved tropospheric ozone profile retrievals using OMI and TES radiances, Geophys. Res. Lett., 34, L01809, https://doi.org/10.1029/2006GL027806, 2007.

Ziemke, J. R., Chandra, S., Duncan, B. N., Froidevaux, L., Bhartia, P. K., Levelt, P. F., and Waters, J. W.: Tropospheric ozone determined from Aura OMI and MLS: evaluation of measurements and comparison with the Global Modeling Initiative's Chemical Transport Model, J. Geophys. Res.-Atmos., 111, D19303, https://doi.org/10.1029/2006JD007089, 2006. 